Research Article

\title{
Research on Dynamic Stability Optimization of Rock Spreader considering Prevention of Geological Subsidence and Local Collapse in Reclamation Area
}

\author{
Baofu Kou $\mathbb{D}^{1}{ }^{1}$ Pengliang Huo, ${ }^{2}$ and Xin Shi ${ }^{1}$ \\ ${ }^{1}$ School of Mechanical Engineering, Taiyuan University of Science and Technology, Taiyuan 030024, China \\ ${ }^{2}$ Shijiazhuang Coal Mining Machinery Co., Ltd., Shijiazhuang 050033, China
}

Correspondence should be addressed to Baofu Kou; koubaofu2004@163.com

Received 15 July 2021; Accepted 29 July 2021; Published 7 August 2021

Academic Editor: Xiaohu Zhang

Copyright (c) 2021 Baofu Kou et al. This is an open access article distributed under the Creative Commons Attribution License, which permits unrestricted use, distribution, and reproduction in any medium, provided the original work is properly cited.

\begin{abstract}
The uneven stacking of waste rock materials caused by the dynamic instability of rock spreaders cannot be ignored for geological subsidence and local collapse in reclamation areas. Based on the dynamic stability of the existing rock spreader, combined with the actual application conditions, the load conditions of the rock spreader are analyzed. The static and dynamic analysis and optimization of the key structures such as the receiving arm, the discharging arm, and the main tower are carried out by using the topology optimization method. The optimized virtual prototype of the whole machine is established to verify its rationality. The research results show that the total weight of key parts such as receiving boom, discharging boom, and the main tower is reduced by about $4.5 \%(4650 \mathrm{~kg})$, the lower-order vibration frequencies below the fifth order of those parts are not within the resonance range, and the stability of the whole machine is greatly improved, which fundamentally solves the problem of uneven rock stacking caused by impact stability. And, the maximum stress and deflection of the whole machine under the worst working conditions meet the actual requirements. The research ideas and conclusions can provide solutions to prevent the subsidence or local collapse of reclamation areas caused by uneven stacking materials.
\end{abstract}

\section{Introduction}

A self-moving rock spreader is a kind of equipment that can orderly discharge the rock and other materials except mineral resources to the fixed dump in the process of open-pit mining, which provides the basic conditions for the reclamation of the mining area after mining $[1,2]$. The development of open-pit mining toward high-speed, large capacity, and automation puts forward not only higher requirements for mining technology but also higher requirements for operating machinery and equipment $[3,4]$. In the early stage, the technology of loading and unloading waste materials by truck and long-distance transportation between mining area and dump has many problems, such as many potential safety hazards, low degree of automation, high emission of waste gas pollution, large consumption of gasoline, and chaotic dump. With the development of mining technology, most open-pit mines combine the rock spreader and belt conveyor to form the rock exhausting system of open-pit mines $[5,6]$. The combination of the two has the advantages of long conveying distance, high conveying efficiency, and good stability $[7,8]$. Therefore, the self-moving rock spreader has become one of the indispensable types of equipment for continuous or semicontinuous high-efficiency mining technology of open-pit mines.

At present, under the action of continuous rainfall, weathering, and human disturbance, the phenomenon of uneven settlement or local collapse often occurs in the reclamation area of waste rock and soil [9-11]. However, the uneven stacking of rock materials by rock spreaders will make this phenomenon more serious and even lead to geological disasters and pollution [12-14]. There are two main reasons for uneven rock materials piled up by rock spreaders. The first is the unreasonable position of lining and line technology. The second is the uneven rock stacking 
caused by the instability of the rock spreader. With the rapid development of intelligent control, accurate control has been achieved in the layout position and line technology [15]. However, the problem of dynamic stability of rock spreaders is easy to be ignored. Therefore, it is urgent to prevent the subsidence or local collapse of reclamation area caused by uneven stacking materials due to the instability of the rock exhauster structure.

Although the research on the rock spreader has achieved phased results, the design of the rock spreader mostly adopts the way of analogy design, and there is a technical bottleneck in the structure refinement design of the rock spreader $[16,17]$. Yang and $\mathrm{Pu}[18]$ optimized the limit device of the PL-2400 rock spreader support truck, which improved the reliability of the rock spreader. Dong and Wang [19] proposed the stacking and discharging process design of rock spreaders based on the scale parameters of waste dump and equipment parameters of rock spreader. Han [20] and Meng et al. [21] optimized the cab and control interface of the rock spreader according to the problems existing in the working environment and control room of the rock spreader. $\mathrm{Hu}$ et al. [22] and Zhang [23] have made a new design for the lubrication system of the rock spreader, which improves the working efficiency and service life of the rock spreader. Yao et al. [24] put forward a method to limit the vibration of the discharging boom of the rock spreader. Therefore, on the basis of the existing research results of the rock exhauster, the formation of a more perfect calculation method for the structure optimization of the rock spreader can not only shorten the design cycle of the rock spreader and promote the standardization and serialization of the rock spreader but also improve the uniformity of the material of the rock spreader and prevent the serious subsidence or landslide in the reclamation area to a certain extent.

Structural topology optimization is an effective lightweight design method to solve complex working conditions [25-27]. In the field of mine engineering, relevant scholars have studied different types of structural parts by using topology optimization theory and achieved good results $[28,29]$. Wu et al. [30] applied the variable density method to optimize the topology of the main arm and the small arm of the hydraulic chisel loader. The result shows that the weight is reduced by $8 \%$, but the stress is reduced and the safety factor is improved. Tang et al. [31] established the topology optimization model of the key structural parts of the feeder by using the variable density method and the substructure method and carried out the optimization. After the optimization, the natural frequency of the structure was increased by $4.17 \%$ and $6.30 \%$, respectively, and the maximum dynamic stress was reduced by $46.4 \%$, which improved the overall stiffness and structural reliability of the feeder. Pang et al. [32] used the topology optimization method to study the lightweight of the track frame of the WK-75 excavator based on multibody dynamics. After topology optimization, the thickness of the main support plate and rib plate of the track frame is reduced, and the material utilization efficiency is improved.

To sum up, relevant scholars have made some progress in structural stability and topology optimization of rock spreaders [33], but they have not formed a complete optimization design method and theory for the dynamic stability of key structures of rock spreaders. According to the field investigation and theoretical analysis, it is easy to produce large impact vibration due to the large self-weight of the key structure of the rock spreader and its low-order frequency is close to the natural frequency. This not only leads to the short service life of the rotary bearing of the receiving boom and the counterweight boom but also causes the failure of the hydraulic cylinder connecting the discharging boom from time to time [34]. More importantly, it will cause the uniform discharge of geotechnical materials by the rock spreader. In view of the above problems, firstly, the actual load conditions of rock spreaders are analyzed, based on this, a static and dynamic analysis of the existing structure was made, and the problems existing in its dynamic stability were discussed. Then, the topology optimization analysis of the three main structural parts of the discharge arm, the receiving arm, and the main tower is carried out by using the variable density topology theory. And then, based on the topology results and combined with the field application conditions, the new design of each structure is carried out. Finally, the static and dynamic verification of the key structural parts after topology optimization is carried out, and the whole machine joint simulation is carried out to verify the correctness of the topology optimization results. Here, it is aimed to explore a set of topology optimization design theories and methods suitable for the key main structural parts of a large rock spreader, so as to improve the dynamic stability of its main structural parts, and make the stress on the structural parts uniform and give full play to the mechanical efficiency of materials. The research conclusion can provide an important guarantee for solving the discharge uniformity of rock spreaders and indirectly curb or prevent the serious settlement or local landslide in the reclamation area of waste rock and soil.

\section{Analysis of Load Characteristics of Rock Spreader}

The rock spreader is mainly composed of receiving system, discharging system, pitching system, counterweight system, main tower, and crawler walking device. The schematic diagram of the whole machine is shown in Figure 1. Taking a certain type of rock spreader as the research object, the main design parameters of this type of rock spreader are shown in Table 1.

In the process of discharging rock, the rock spreader will be subjected to the complex load, which is accompanied by the process of full load starting and braking, sudden unloading, and climbing with a load. In the calculation process, the load value is determined according to the comprehensive consideration of the material conveying capacity and the external environmental load $[35,36]$. According to the code for the design of steel structure of mobile continuous bulk material handling equipment, the load of rock spreader is quantified. Then, it is designed and checked according to the following working conditions [37, 38]: 


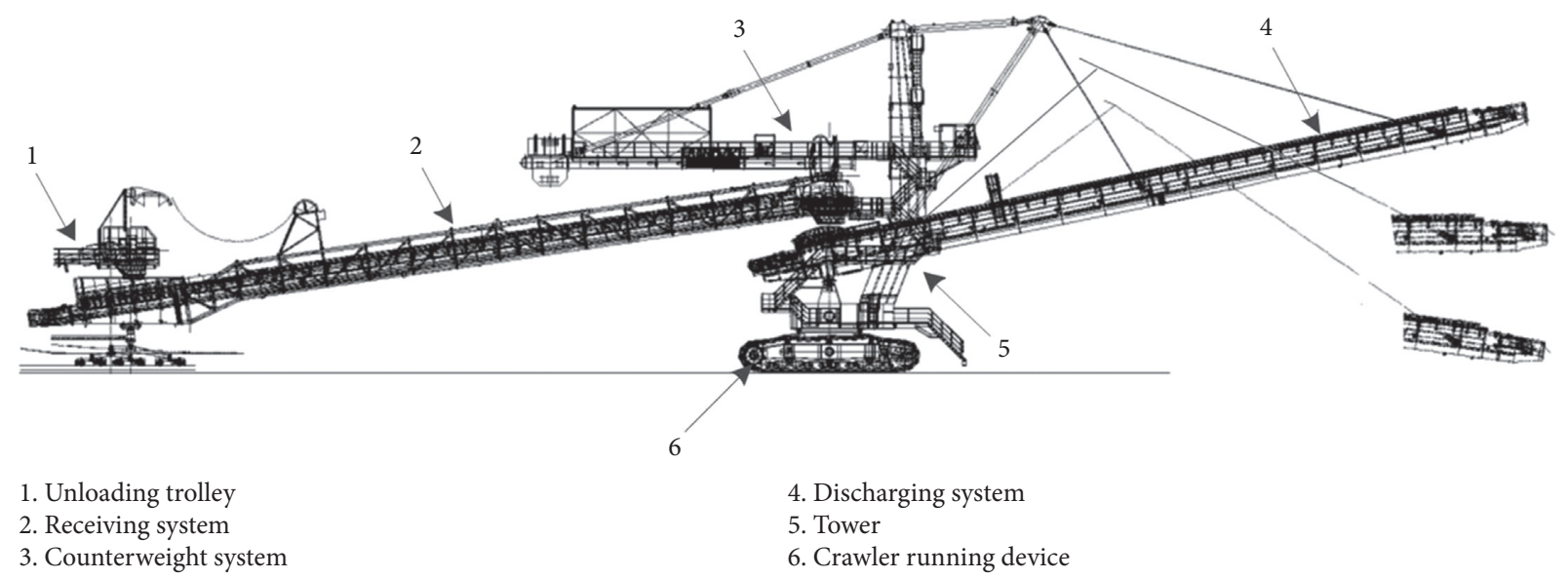

FIGURE 1: Structure diagram of the spreader. 1: unloading trolley; 2: receiving system; 3: counterweight system; 4: discharging system; 5 : tower; 6: crawler running device.

TABLE 1: Main design parameters of rock spreader.

\begin{tabular}{lc}
\hline Main design parameters & Value \\
\hline Rated conveying capacity & $4500 \mathrm{t} / \mathrm{h}$ \\
Average grounding voltage under normal operation & $\leq 110 \mathrm{kPa}$ \\
Radius of gyration & $50 \mathrm{~m}$ \\
Length of discharging boom & $50 \mathrm{~m}$ \\
Maximum upward angle of discharging boom & $13^{\circ}$ \\
Maximum downward angle of discharging boom & $4^{\circ}$ \\
Length of the receiving boom & $50 \mathrm{~m}$ \\
Width of conveyor belt & $1.4 \mathrm{~m}$ \\
Speed of conveyor belt & $4 \mathrm{~m} / \mathrm{s}$ \\
Speed of travel & $0 \sim 8 \mathrm{~m} /$ \\
Working gradient & $\mathrm{min}$ \\
Walking gradient & $1: 20$ \\
\hline
\end{tabular}

Condition I: the rock spreader is only subjected to selfweight load (no-load working condition)

Condition II: normal operation of rock spreader (rated load with wind load)

Condition III: abnormal operation (rated load with wind load and seismic load)

To alleviate the impact of the rock spreader on the receiving boom in the working process, the left end of the receiving boom is connected with the receiving boom support trolley through the guide wheel group and guide rail. The length of the guide wheel group is $2500 \mathrm{~mm}$, and the length of the guide rail at the left end of the receiving boom is $7500 \mathrm{~mm}$. In the working process, the position of the guide wheel group determines the three typical working positions of the receiving boom. The three positions are as follows: the guide wheel of the support car of the unloading car is located in the left limit position, the middle position, and the right limit position of the guide rail. There are three typical working positions for the discharging boom of rock discharging machine: the discharging boom is horizontal, the discharging boom is upward $13^{\circ}$, and the discharging boom is downward $4^{\circ}$.
Influence analysis of each part: (1) The receiving boom of the rock spreader supports the whole receiving conveyor to complete the receiving operation. The left end of the receiving boom is connected with the receiving boom support trolley through the guide wheel guide rail, and the right end is suspended on the counterweight boom through the slewing bearing. The weight of the receiving boom directly affects the service life of the slewing bearing. (2) The discharging boom supports the whole discharging conveyor to complete the discharging operation. The discharging boom mainly realizes the pitching movement of the discharging boom through the hydraulic cylinder. The quality of the discharging boom directly affects the service life of the hydraulic cylinder and other parts. (3) The main tower is used to fix the discharging boom and the counterweight boom. The above three key structural parts occupy a very important position in the upper structure of the rock spreader, and their structural rationality directly affects the working flexibility and energy consumption of the whole machine.

The load and working condition combination of receiving boom are shown in Table 2. The load and working condition combination of the discharging boom are shown in Table 3.

\section{Static and Dynamic Characteristics Analysis of Key Structure of Rock Spreader}

\subsection{Finite Element Analysis of Structure}

3.1.1. Finite Element Analysis Theory of Structure [39]. The dynamic equation of the structure is as follows:

$$
[M]\{\ddot{x}\}+[C]\{\dot{x}\}+[K]\{x\}=\{F(t)\},
$$

where $[M]$ is the structural mass matrix, $[C]$ is the damping matrix, $[K]$ is the stiffness matrix, $\{x\}$ is the displacement vector, and $\{F(t)\}$ is the force vector. 
TABle 2: The load and working condition combination of receiving boom.

\begin{tabular}{|c|c|c|c|c|c|}
\hline Load type & Name & Size $(\mathrm{N})$ & \multicolumn{3}{|c|}{ Type of working condition } \\
\hline \multirow{9}{*}{ Basic load } & Deadweight of receiving boom & 359170 & I & II & III \\
\hline & Conveyor belt & 75000 & $\checkmark$ & $\checkmark$ & $\checkmark$ \\
\hline & Roller & 77700 & $\checkmark$ & $\sqrt{ }$ & $\checkmark$ \\
\hline & Materials & 158500 & & $\checkmark$ & $\checkmark$ \\
\hline & Walking platform and railings & 128800 & $\checkmark$ & $\checkmark$ & $\checkmark$ \\
\hline & $\begin{array}{l}\text { Buffer bed and } \\
\text { receiving chute }\end{array}$ & 87390 & $\checkmark$ & $\checkmark$ & $\checkmark$ \\
\hline & Discharging chute & 37990 & $\checkmark$ & $\checkmark$ & $\checkmark$ \\
\hline & Head roller and driving device & 69830 & $\checkmark$ & $\checkmark$ & $\checkmark$ \\
\hline & Tail roller and tightening device & 29830 & $\checkmark$ & $\checkmark$ & $\checkmark$ \\
\hline Additional load & Wind load & 10428 & & $\checkmark$ & $\checkmark$ \\
\hline Special loads & Seismic load & & & & $\checkmark$ \\
\hline
\end{tabular}

TABLE 3: The load and working condition combination of discharging boom.

\begin{tabular}{|c|c|c|c|c|c|}
\hline Load type & Name & Size $(\mathrm{N})$ & \multicolumn{3}{|c|}{ Type of working condition } \\
\hline \multirow{9}{*}{ Basic load } & Deadweight of receiving boom & 263030 & I & II & III \\
\hline & Conveyor belt & 65000 & $\checkmark$ & $\checkmark$ & $\checkmark$ \\
\hline & Roller & 55000 & $\checkmark$ & $\checkmark$ & $\checkmark$ \\
\hline & Materials & 158500 & & $\checkmark$ & $\checkmark$ \\
\hline & Walking platform and railings & 112930 & $\checkmark$ & $\checkmark$ & $\checkmark$ \\
\hline & Buffer bed and receiving chute & 48180 & $\checkmark$ & $\checkmark$ & $\checkmark$ \\
\hline & Discharging chute & 25000 & $\checkmark$ & $\checkmark$ & $\checkmark$ \\
\hline & Head roller and driving device & 96720 & $\checkmark$ & $\checkmark$ & $\checkmark$ \\
\hline & Tail roller and tightening device & 66260 & $\checkmark$ & $\checkmark$ & $\checkmark$ \\
\hline Additional load & Wind load & 9870 & & $\checkmark$ & $\checkmark$ \\
\hline Special loads & Seismic load & & & & $\checkmark$ \\
\hline
\end{tabular}

For the static analysis of linear structure, the influence of time is ignored. The following relationship can be deduced by combining (1):

$$
[K]\{x\}=\{F\},
$$

where $[F]$ is the static load without considering the time effect.

The stress and strain values of the structure under load can be obtained by solving equation (2). According to the deformation value and stress value, we can check whether the structure meets the user requirements under different working conditions.

The structural strain can be expressed as

$$
\{\varepsilon\}=\partial\{f\}=\partial[N]\{\delta\}^{e}=[B]\{\delta\}^{e},
$$

where $\{\varepsilon\}$ is the strain matrix, $\{f\}$ is the concentrated load matrix, $[N]$ is the shape function matrix, $\{\delta\}^{e}$ is the node displacement matrix, and $[B]$ is the constant strain element matrix.

The structural stress can be expressed as

$$
\{\sigma\}=[D]\{\varepsilon\}=[D][B]\{\varepsilon\}^{e}=[S]\{\varepsilon\}^{e},
$$

where $\{\sigma\}$ is the stress matrix, $[D]$ is the elastic matrix, $\{\varepsilon\}$ is the strain matrix, $\{\varepsilon\}^{e}$ is the node displacement matrix, and $[S]$ is the constant stress element matrix.
Q345E is mainly used as the boom material of the rock spreader. In view of the complexity of the loads, the third strength theory or the fourth strength theory is needed to check the strength of the rock spreader structure. Because the fourth strength theory mainly considers the influence of the principal stress $\sigma_{2}$, it is closer to reality than the third strength theory. Therefore, the static strength of the rock spreader structure is checked according to the stress value $\sigma_{e}$ calculated by the fourth strength theory.

The von Mises stress can be expressed as

$$
\sigma_{e}=\sqrt{\left\{\frac{1}{2}\left[\left(\sigma_{1}-\sigma_{2}\right)^{2}+\left(\sigma_{2}-\sigma_{3}\right)^{2}+\left(\sigma_{3}-\sigma_{1}\right)^{2}\right]\right\}},
$$

where $\sigma_{1}, \sigma_{2}$, and $\sigma_{3}$ are the three principal stresses of any particle, and $\sigma_{1}>\sigma_{2}>\sigma_{3}$.

The strength check standard is as follows:

$$
\sigma_{e} \leq[\sigma]
$$

where $\sigma_{e}$ is the maximum equivalent stress and $[\sigma]$ is the allowable stress.

The structural stiffness can be expressed as

$$
[K]^{e}=[B]^{T}[D][B] V,
$$

where $[K]^{e}$ is the element stiffness matrix and $V$ is the unit tetrahedral volume. 
TABLE 4: Allowable stress under different working conditions.

\begin{tabular}{lccc}
\hline Parameter name & Working condition I & Working condition II & Working condition III \\
\hline Safety coefficient & 1.5 & 1.33 & 1.2 \\
Q345E $(\mathrm{MPa})$ & 230 & 259 & 288 \\
\hline
\end{tabular}

The allowable tensile stress of Q345E used in the boom structure of the rock spreader is $[\sigma]=345 \mathrm{MPa}$, but the allowable safety factor is clearly different under different working conditions. According to the "code for the design of steel structure of mobile continuous bulk handling equipment," different safety factors should be selected for the structure of rock spreader under different working conditions [36], and the allowable stress table is shown in Table 4.

According to "the code for design of steel structures," the allowable deflection value of the boom of rock spreader is $L / 250$ [39]. The length of the receiving boom is $50 \mathrm{~m}$, so the allowable deflection is $250 \mathrm{~mm}$. The length of discharging boom is $21.6 \mathrm{~m}$, so the allowable deflection is $86.4 \mathrm{~mm}$. The height of the main tower is $20 \mathrm{~m}$, so the allowable deflection is $80 \mathrm{~mm}$.

\subsubsection{Establishment of the 3D Solid Model of the Key} Structure. The assignment of structural material properties is as follows: elastic modulus $E=210 \mathrm{GPa}$, Poisson's ratio $\mu=3$, density $\rho=7850 \mathrm{~kg} / \mathrm{m}^{3}$, and yield strength $\sigma=345 \mathrm{MPa}$. To improve the efficiency of simulation, on the basis of not affecting the accuracy of the key object, some secondary structural parts are simplified as follows [40]:

(1) Some features such as threaded holes, fillets, and chamfers are simplified

(2) The receiving conveyor, walking platform railing, driving device, and reversing device are added to the relevant boom in the form of load

(3) The influence of the connecting plate on the structure is ignored

(4) The weld and bolt connection are ignored

(5) The wire rope is established by using the line body in the submodule "Geometry" of "ANSYS Mechanical"

The models of receiving boom, discharging boom, and main tower are shown in Figure 2.

\subsubsection{Finite Element Solution and Analysis of Key Parts}

(1) Finite Element Analysis of Receiving Boom. The guide rail at the left end of the receiving boom is supported by the guide wheel of the supporting trolley, so the translational degrees of freedom along the direction of the guide rail are released, and the degrees of freedom in other directions are limited. The right end lug is hinged with the fixed end lug of the unloading boom, so the degree of freedom of rotation around the hanging shaft is released at the hinge, and the degree of freedom in other directions is limited.

As shown in Figure 3, under working condition III, the maximum deformation of the receiving boom is $66.74 \mathrm{~mm}$, which occurs in the center of the receiving boom span; the maximum stress is $190.67 \mathrm{MPa}$, which occurs on the vertical steel plate at the left end of the receiving boom.

(2) Finite Element Analysis of Discharging Boom. According to the matching condition of the discharging boom and the rotary platform, its abutments can be set as a hinge joint; that is, it can limit the movement degree of freedom in $X Y Z$ direction and the rotation degree of freedom around $X$ - and $Z$-axis and release the rotation degree of freedom around $Y$ axis. The connection between the strut and the hydraulic cylinder is hinged; that is, the movement degree of freedom in $X Y Z$ direction and the rotation degree of freedom around the $X$ - and $Z$-axis are limited, and the rotation degree of freedom around the $Y$-axis is released.

When adding a load, in order to better simulate the load of walking platform railings and conveyors, the model is processed by the design modeler in ANSYS Workbench, and the imprint surface is added at the position where the load needs to be applied in the model, so as to apply the load more accurately [41].

It can be seen from Figure 4 that the total deformation displacement of the discharging boom under condition III is the largest, which occurs between the second and third hanging points, and the maximum deformation is $48.259 \mathrm{~mm}$. Under condition III, the maximum stress of the discharging boom is $168.77 \mathrm{MPa}$, which occurs at the connection between the diagonal web member and the main chord between the two groups of suspension points, and the stress distribution in most other areas is about $90 \mathrm{MPa}$ or less.

(3) Finite Element Analysis of Main Tower. It can be seen from Figure 5 that the maximum deformation of the tower under adverse conditions is $56.685 \mathrm{~mm}$, and the maximum deformation occurs at the top of the main tower. The maximum stress value of the main tower is $218.06 \mathrm{MPa}$, and the maximum stress position occurs at the connection between the counterweight boom and the main tower. Because there is no stiffener at the junction of the original tower, the structure is relatively weak.

To sum up, by comparing the allowable values of stress in Table 4 and the allowable values of deflection and deformation mentioned above and analyzing Figures 3-5, it can be seen that the maximum stress value and maximum deflection and deformation value of key parts such as receiving boom, discharging boom, and main tower are within the safe range, but they are all abundant and have large optimization space. In addition, the distribution of stress and deflection in different parts is uneven, and the stress and deflection in many parts are very small, so it is difficult to play the maximum utility of materials.

3.2. Modal Analysis of Boom. The receiving boom and discharging boom are equipped with belt conveyors, driving 


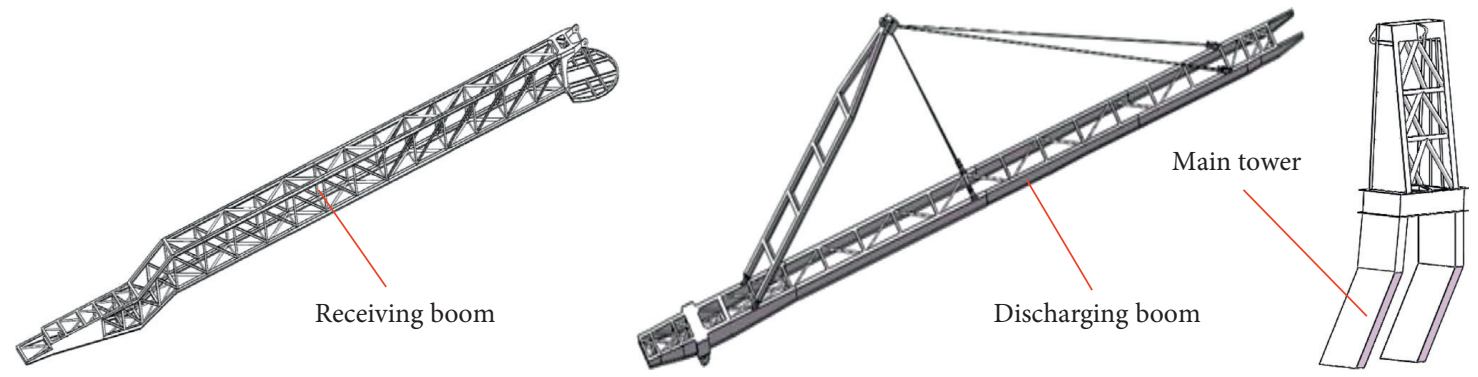

FIGURE 2: The models of receiving boom, discharging boom, and main tower.

I: gongkuang III

Total Deformation

Type: Total Deformation

Unit: $\mathrm{mm}$

Time: 1

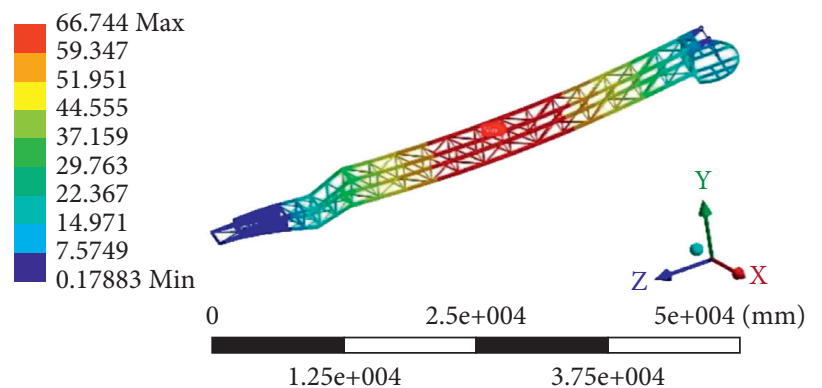

I: gongkuang III

Equivalent Stress

Type: Equivalent (von-Mises) Stress

Unit: $\mathrm{MPa}$

Time: 1

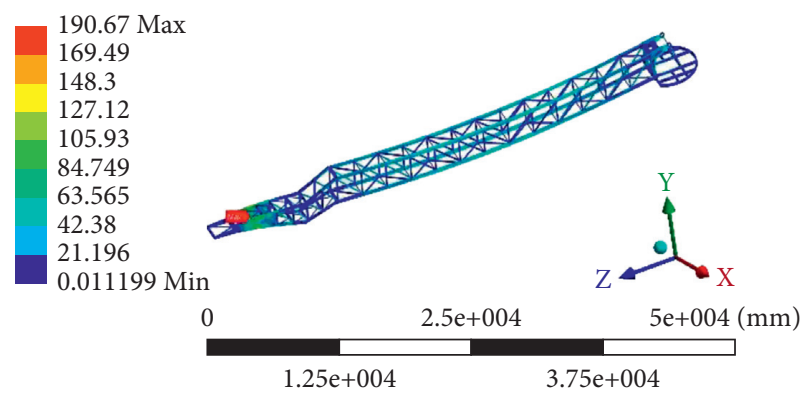

FIGURE 3: Deformation and stress nephogram of receiving boom under working condition III.

I: gongkuang III

Total Deformation

Type: Total Deformation

Unit: $\mathrm{mm}$

Time: 1

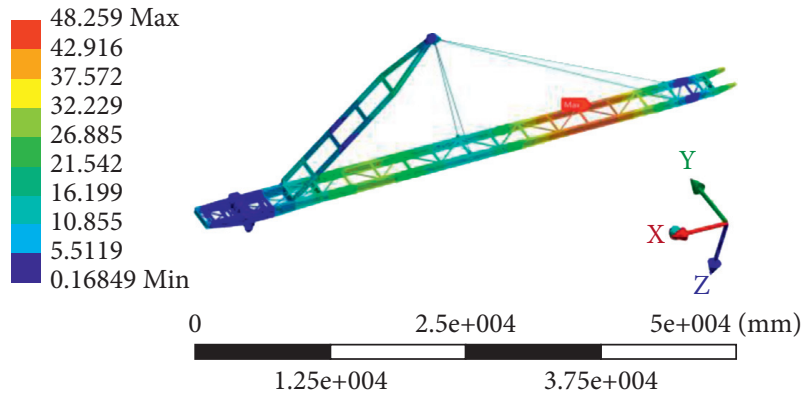

I: gongkuang III

Equivalent Stress

Type: Equivalent (von-Mises) Stress

Unit: MPa

Time: 1

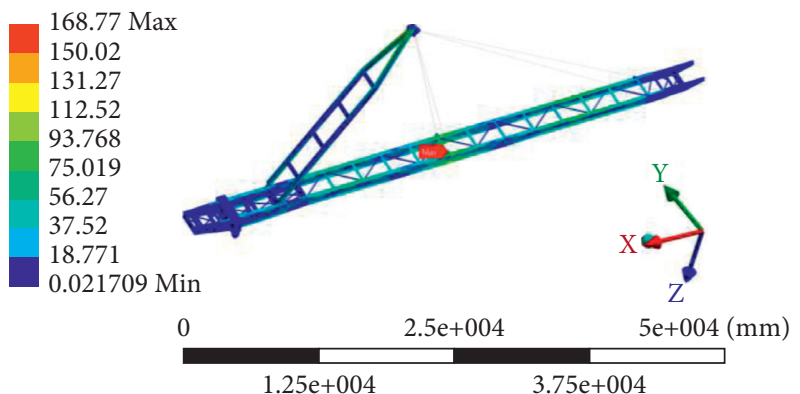

FIGURE 4: Deformation and stress nephogram of discharging boom under working condition III.

motors, idlers, etc. The periodic work of these parts will inevitably bring the excitation sources to the boom and affect the dynamic performance of the boom. The boom will produce complex vibration and deformation under the excitation of idler and motor, so the research on the dynamic characteristics of boom has a great impact on the safety and service life of boom. As the basis of dynamic analysis, modal analysis is a common method of structural dynamic characteristics analysis. Modal analysis can be used to solve the natural frequency and main mode of vibration of the boom of the rock spreader [42], and the frequency and resonance position of the boom of the rock spreader can be obtained.
According to the analysis results, the optimal design of the rock spreader can be carried out, which provides a theoretical basis for improving the dynamic characteristics of the boom.

When the speed of the driving motor is $1485 \mathrm{r} / \mathrm{min}$, the excitation frequency of the driving motor is $f=1485$ / $60=24.75 \mathrm{~Hz}$. The roller rotation excitation should be calculated according to the belt speed. Under the rated working condition of the rock spreader, the belt speed $v=4 \mathrm{~m} / \mathrm{s}$, so the excitation frequency $f=1000 v / \pi \mathrm{d}=4000 / 159 \pi=8 \mathrm{~Hz}$. If the $\pm 15 \%$ resonance band is selected [43], the resonance band caused by the idler is in the range of $6.8 \mathrm{~Hz} \sim 9.2 \mathrm{~Hz}$. 

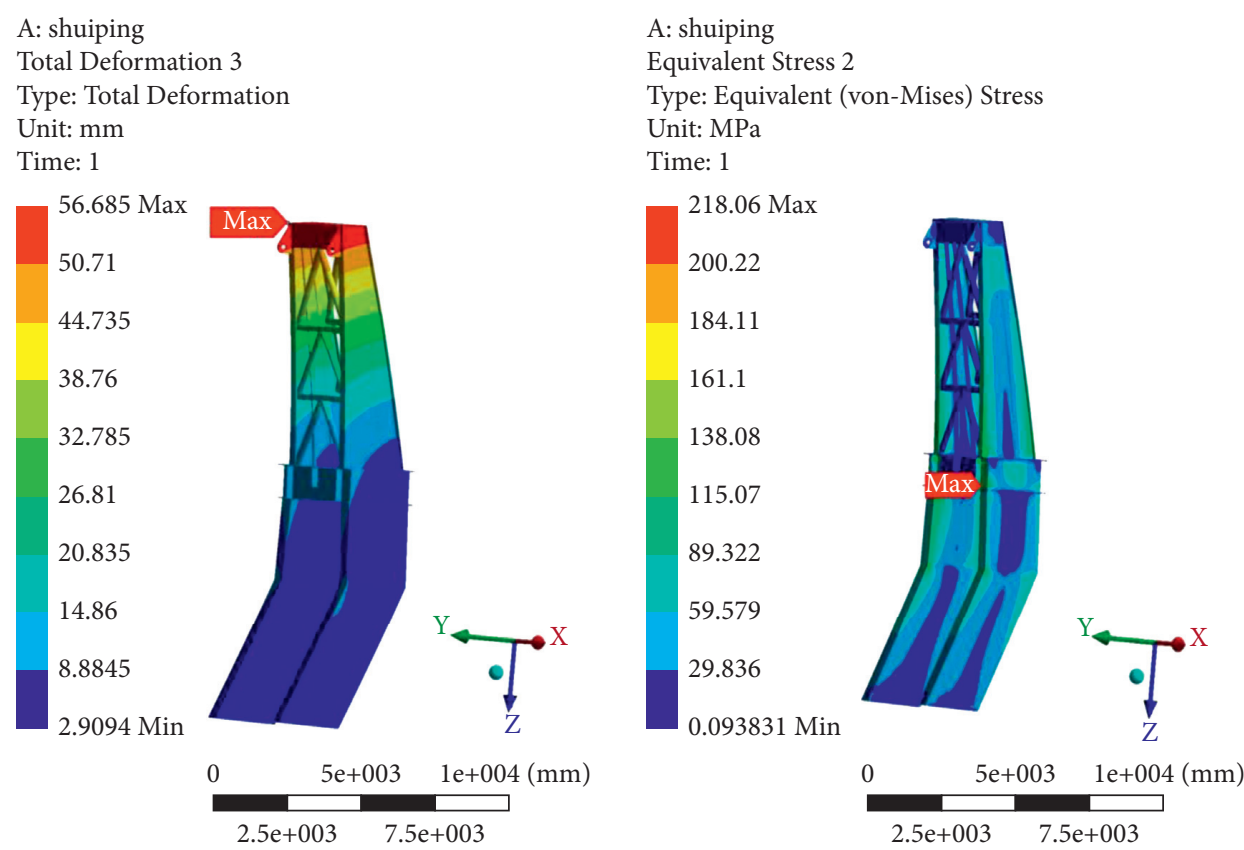

Figure 5: Deformation and stress nephogram of the main tower under severe working conditions.

3.2.1. Modal Analysis of Receiving Boom. Modal calculation of the receiving boom is carried out by the modal module in ANSYS Workbench. The degree of freedom around the $x$-axis is released at the hanging point of the right end of the receiving boom, and the other degrees of freedom are limited. The degrees of freedom of the left end of the boom along the $z$-axis are released, and all degrees of freedom in other directions are constrained. The first six modes of the boom can be obtained by solving the mode of the boom, as shown in Figure 6 .

The frequency of the receiving boom is far from that of the motor, so it will not be affected by the vibration frequency of the motor. The fifth-order natural frequency of the receiving boom is $7.60 \mathrm{~Hz}$, which is easy to cause resonance in the resonance band of the idler.

According to the vibration mode diagram of the first six modes in Figure 6 and the vibration mode description in Table 5, it can be seen that the stiffness of the head of the receiving boom is weak, and the multistage vibration modes show the maximum vibration mode at the head of the receiving boom. The first natural frequency of the receiving boom is low, so it is necessary to optimize the structure of the receiving boom, so as to improve the low natural frequency of the receiving boom, improve its dynamic performance, and reduce the risk of resonance.

3.2.2. Modal Analysis of Discharging Boom. In the same way, constraints are imposed on the discharging boom and modal analysis is carried out to obtain the first six modes. The calculation results are shown in Figure 7.

It can be seen from the above Figure 7 and Table 6 that the natural frequencies of each order of the discharging boom are far different from the excitation frequency of the motor, so the motor excitation will not cause resonance. However, the fifth- and sixth-order natural frequencies of the discharging boom are $8.36 \mathrm{~Hz}$ and $8.93 \mathrm{~Hz}$, respectively, which are all within the resonance band of the idler and are easy to cause resonance.

\section{Lightweight of Key Parts of Rock Spreader}

\subsection{Basic Theory of Topology Optimization}

4.1.1. Topology Optimization Based on the Variable Density Method [44, 45]. The topology optimization module of ANSYS Workbench uses the variable density method to optimize the structure topology. Firstly, the continuum structure is discretized by the finite element method, and the relationship between relative density and elastic modulus is expressed in the form of the density interpolation function of continuous variables. Then, taking the relative density of the elements as the optimization variable, each element corresponds to an optimization variable in the optimization process. By changing the value of each optimization variable, the elastic modulus of each element and the stiffness matrix of the structure are changed, so that the material is redistributed in the matrix model, and finally, the optimal structure meeting the stress, deformation, and other constraints is obtained.

4.1.2. Mathematical Algorithm for Topology Optimization [44-46]. The Lagrange multiplier method is an important method to solve the extremum problem and conditional stationary value problem. Its central idea is to transform the extremum problem of original function under constraint condition into the extremum problem of the functional under unconstrained conditions, that is, to complete the transformation from a constrained optimization problem to an unconstrained optimization problem. Since the 


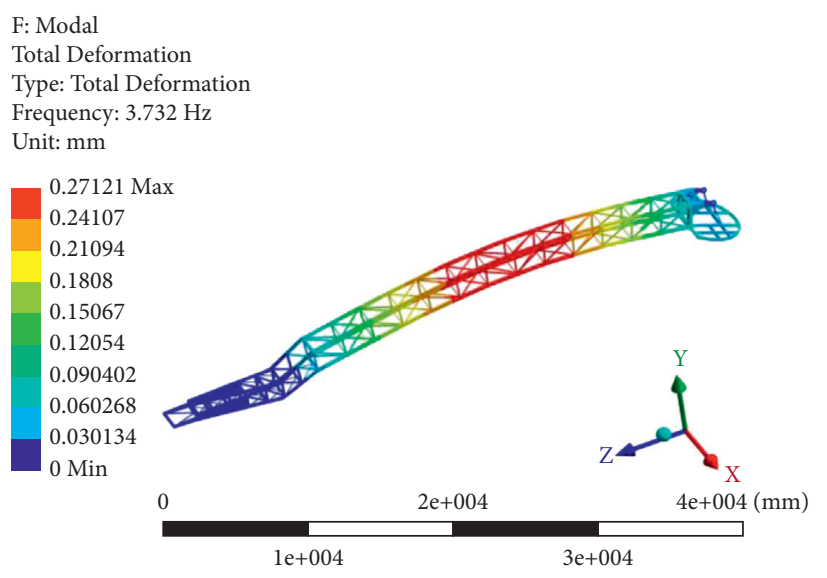

(a)

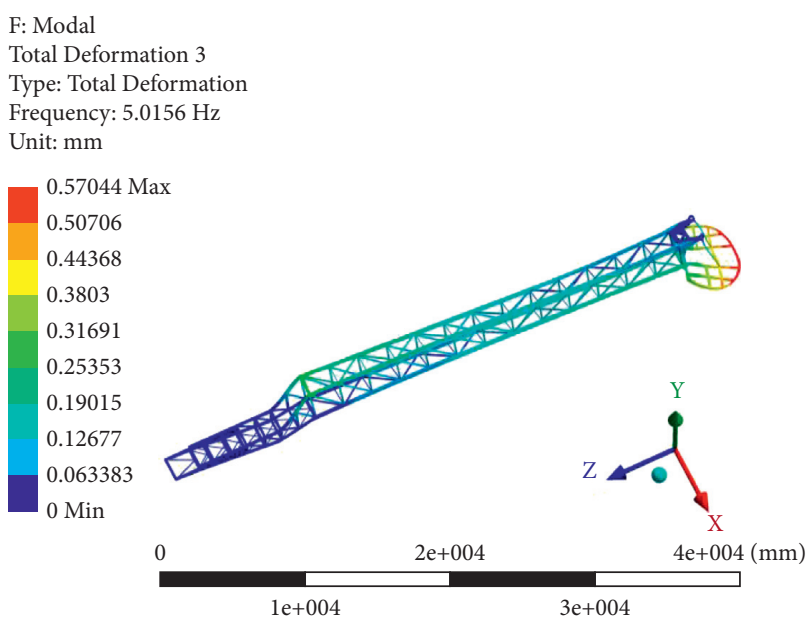

(c)

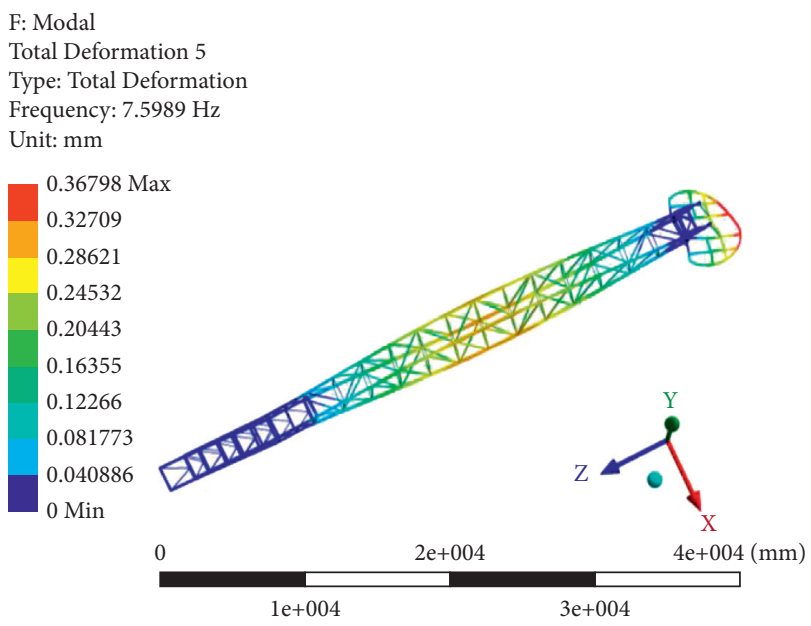

(e)

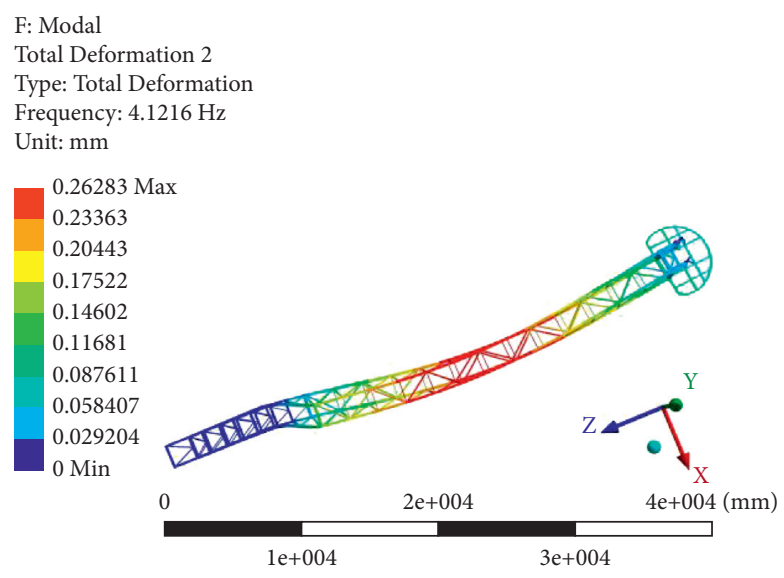

(b)

F: Modal

Total Deformation 4

Type: Total Deformation

Frequency: $6.7786 \mathrm{~Hz}$

Unit: $\mathrm{mm}$

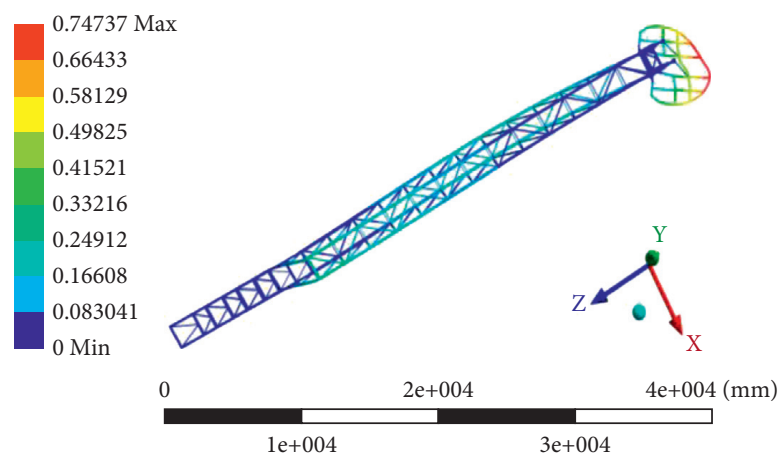

(d)

F: Modal

Total Deformation 6

Type: Total Deformation

Frequency: $10.457 \mathrm{~Hz}$

Unit: $\mathrm{mm}$

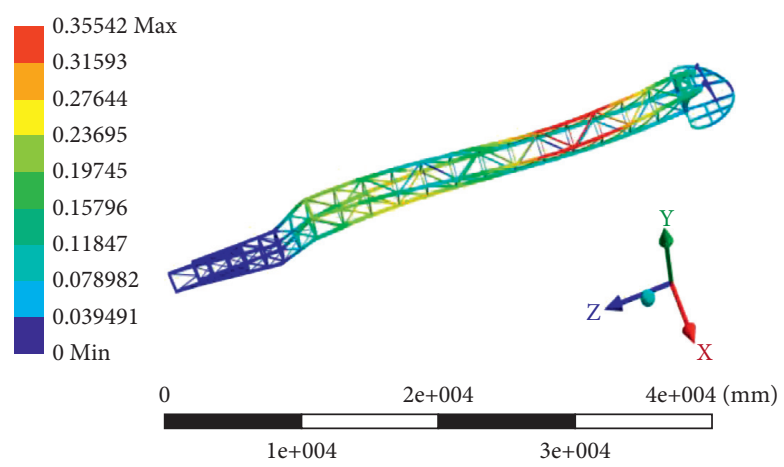

(f)

Figure 6: The vibration mode diagram of the first six modes of the receiving boom before optimization. (a) The first mode. (b) The second mode. (c) The third mode. (d) The fourth mode. (e) The fifth mode. (f) The sixth mode.

introduction of the Lagrange multiplier method simplifies the mathematical calculation process, the Lagrange multiplier method is selected to solve the variable density topology optimization problems.
It is assumed that the density of each virtual cell in the topology optimization space is $\rho_{i}$, and the actual density of the optimized space is $\rho_{0}$. The relationship between the virtual density $\rho_{i}$ and actual density $\rho_{0}$ can be expressed as follows: 
Table 5: Description of the first six natural frequencies and vibration modes of receiving boom.

\begin{tabular}{|c|c|c|c|}
\hline Order & $\begin{array}{l}\text { Natural frequency } \\
\qquad(\mathrm{Hz})\end{array}$ & $\begin{array}{l}\text { Total amplitude } \\
\qquad(\mathrm{mm})\end{array}$ & Mode shapes \\
\hline 1 & 3.73 & 0.27 & The midspan is bent in the positive direction of the $y$-axis \\
\hline 2 & 4.12 & 0.27 & The midspan is bent in the positive direction of the $x$-axis \\
\hline 3 & 5.02 & 0.58 & $\begin{array}{l}\text { The whole boom is slightly twisted, and the head of the receiving boom is twisted along the } \\
\qquad x \text {-axis }\end{array}$ \\
\hline 4 & 6.78 & 0.75 & $\begin{array}{c}\text { The tail of the boom turns to the positive direction of the } x \text {-axis, and the head of the boom } \\
\text { turns around the } y \text {-axis }\end{array}$ \\
\hline 5 & 7.60 & 0.37 & The middle of the boom is twisted around the $z$-axis, and the head is about the $x$-axis \\
\hline 6 & 10.46 & 0.36 & $\begin{array}{l}\text { The position near the tail of the boom turns to the negative direction of the } x \text {-axis, and the } \\
\text { position near the head turns to the positive direction of the } x \text {-axis }\end{array}$ \\
\hline
\end{tabular}

Total Deformation

Type: Total Deformation

Frequency: $1.6825 \mathrm{~Hz}$

Unit: $\mathrm{mm}$

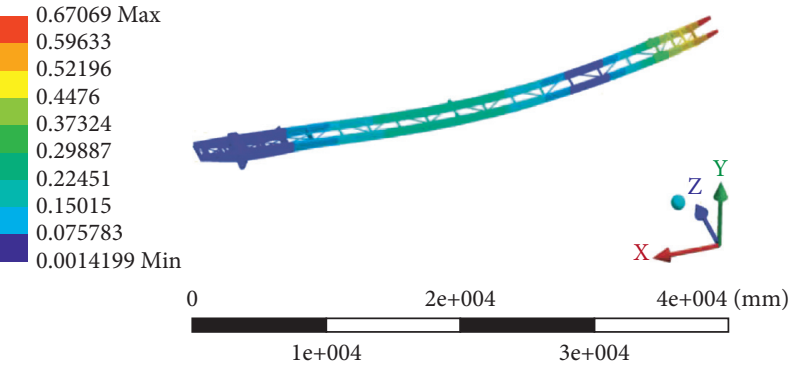

(a)

Total Deformation 3

Type: Total Deformation

Frequency: $4.7828 \mathrm{~Hz}$

Unit: $\mathrm{mm}$

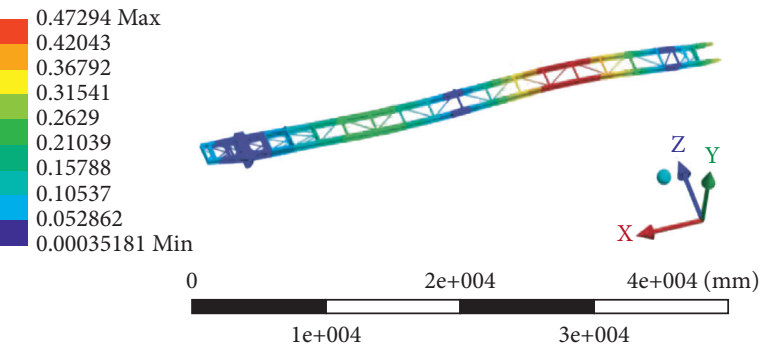

(c)

Total Deformation 5

Type: Total Deformation

Frequency: $8.356 \mathrm{~Hz}$

Unit: $\mathrm{mm}$

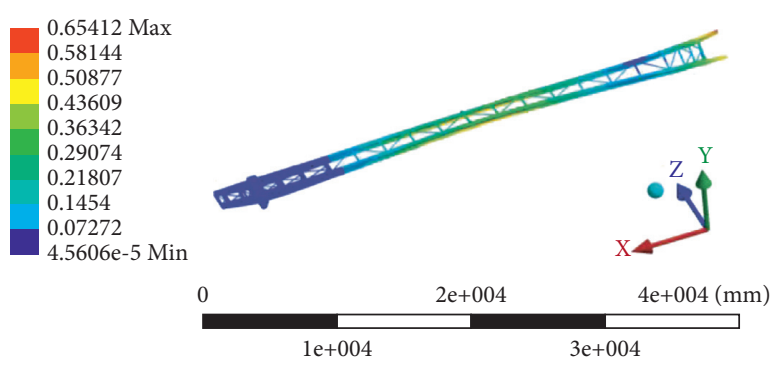

(e)
Total Deformation 2

Type: Total Deformation

Frequency: $3.3743 \mathrm{~Hz}$

Unit: $\mathrm{mm}$
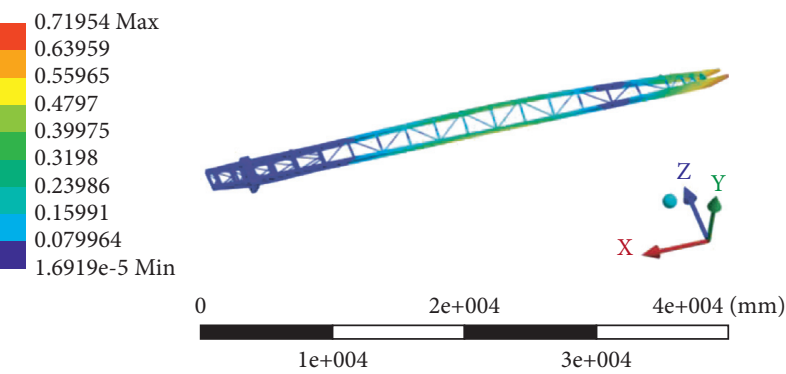

(b)

Total Deformation 4

Type: Total Deformation

Frequency: $6.5923 \mathrm{~Hz}$

Unit: $\mathrm{mm}$

$0.68522 \mathrm{Max}$
0.60909
0.53296
0.45683
0.3807
0.30457
0.22844
0.1523
0.076174
$4.3381 \mathrm{e}-5 \mathrm{Mi}$
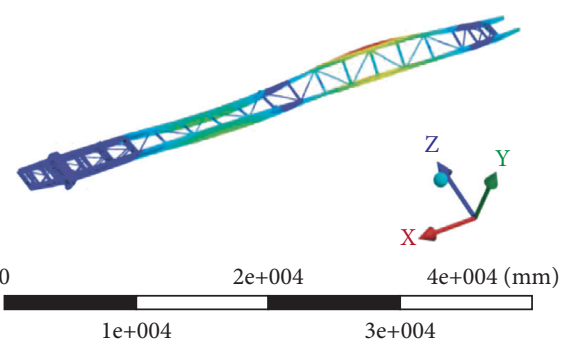

(d)

Total Deformation 6

Type: Total Deformation

Frequency: $8.93266 \mathrm{~Hz}$

Unit: $\mathrm{mm}$

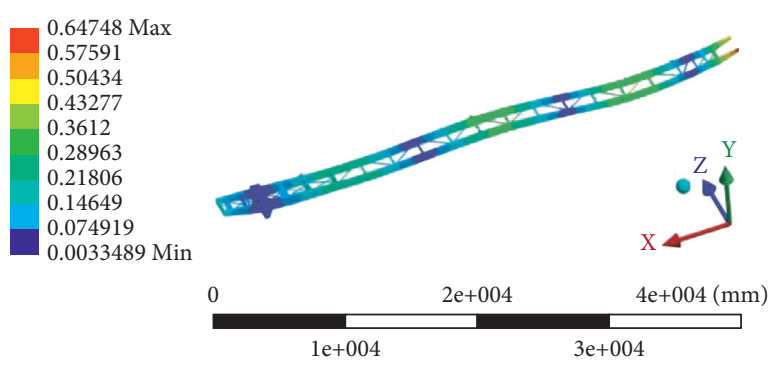

(f)

Figure 7: The vibration mode diagram of the first six modes of the discharging boom before optimization. (a) The first mode. (b) The second mode. (c) The third mode. (d) The fourth mode. (e) The fifth mode. (f) The sixth mode. 
TABLE 6: Description of first six natural frequencies and vibration modes of receiving boom.

\begin{tabular}{cccc}
\hline Order & $\begin{array}{c}\text { Natural frequency/ } \\
\mathrm{Hz}\end{array}$ & $\begin{array}{c}\text { Total amplitude/ } \\
\mathrm{mm}\end{array}$ & Mode shapes \\
\hline 1 & 1.68 & 0.67 & The middle span is around the $Z$-axis and bending in the positive direction of the $y$-axis \\
2 & 3.37 & 0.72 & $\begin{array}{c}\text { The head of the boom is twisted around the } x \text {-axis } \\
3\end{array}$ \\
4.78 & 0.47 & $\begin{array}{c}\text { Bending occurs between two groups of hanging points of boom } \\
4\end{array}$ \\
5 & 8.59 & 0.69 & The two groups of hanging points of the boom are twisted in the opposite direction \\
around the $x$-axis
\end{tabular}

$$
\rho_{i}=x_{i} \rho_{0}
$$

where $x_{i}$ is the relative density of elements and $i$ is the total number of all elements in the optimization space.

Then, when the relative density $x_{i}=1$, it means that the entity is here; when the relative density $x_{i}=0$, it means that the hole is hollowed out. The relative density $x_{i}$ is defined as the threshold value in the software. Setting different threshold values, the topological results are different. Of course, it is necessary to ensure that $0 \leq x_{i} \leq 1$. To make the relative density $x_{i}$ converge to 0 or 1 , a penalty factor $p$ is introduced. $K_{i}$ is used to represent the relative stiffness of the $i$-th element, and $K_{0}$ represents the inherent stiffness of the topological space. The relationship between relative stiffness and inherent stiffness is as follows:

$$
K_{i}=\left(x_{i}\right)^{P} K_{0} .
$$

According to Hooke's Law,

$$
F=K U,
$$

where $F$ is the load, $K$ is the stiffness matrix, and $U$ is the displacement.

The flexibility and stiffness are reciprocal to each other. If the flexibility is $C$, that is,

$$
C=\frac{1}{K}
$$

Substituting equation (11) into equation (10), we can obtain the following results:

$$
C=F^{T} U=U^{T} K U
$$

The objective of topology optimization is to minimize the flexibility of the structure, that is, to maximize the material stiffness. The volume ratio before and after optimization is taken as the constraint condition. The relative density of each unit in the topology optimization space is taken as the design variable. On the basis of the above, the mathematical model of topology optimization can be obtained as follows:

Design variable: $X=\left\{x_{1}, x_{2}, \ldots x_{n}\right\}^{T}$

Objective function: $C=\min F(X)=F^{T} U$

Constraints: $k \geq V_{1} / V_{0}$

$$
\begin{aligned}
& 0<x_{\text {min }} \leq x_{i} \leq x_{\text {max }} \leq 1 \\
& F=K U
\end{aligned}
$$

where $k$ is the set ratio of surplus material, which is the decisive parameter to be set before topology optimization, and $v_{1}$ is the total volume before topology optimization; $x_{\min }$ and $x_{\max }$ are the minimum value and the maximum value of the relative density value $x_{i}$ of the element, respectively. Limiting the value range of $x_{i}$ can ensure that the structure will not produce a singular total stiffness matrix.

Based on the mathematical model of topology optimization and Lagrange multiplier method, the constructed function can be expressed as follows:

$$
L=C+\lambda_{0}\left(V-f V_{0}-V_{1}\right)+\lambda_{1}^{T}(K U-F)+\sum_{i=1}^{n} \lambda_{2}^{i}\left(x_{\min }-x_{i}\right)+\sum_{i=1}^{n} \lambda_{3}^{i}\left(x_{i}-x_{\min }\right)
$$

When the function takes the extremum,

$$
\frac{\partial L}{\partial x_{i}}=0, \quad i=1,2, \ldots, n .
$$

By deriving $x_{i}$ from both sides of equation (14) and simplifying it, the following equation can be obtained:

$$
\frac{\partial L}{\partial x_{i}}=\frac{\partial U^{T}}{\partial x_{i}} K U+U^{T} \frac{\partial K}{\partial x_{i}}+U^{T} K \frac{\partial U}{\partial x_{i}}+\lambda_{0} V_{i}+\lambda_{1}^{T}\left(\frac{\partial K}{\partial x_{i}} U+K \frac{\partial U}{\partial x_{i}}\right) .
$$

By deriving $x_{\mathrm{i}}$ from both sides of equation (10), the following equation can be obtained:

$$
\frac{\partial F}{\partial x_{i}}=\frac{\partial F}{\partial x_{i}} U+K \frac{\partial U}{\partial x_{i}}=0
$$

Taking equation (17) into equation (16), the following equation can be obtained:

$$
\frac{\partial L}{\partial x_{i}}=U^{T} \frac{\partial K}{\partial x_{i}} U+\lambda_{0} V_{i}+\lambda_{1}^{T} \frac{\partial K}{\partial x_{i}}+\frac{\partial U}{\partial x_{i}}\left(2 U^{T}+\lambda_{1}^{T} K\right),
$$


where $\lambda_{1}^{T}$ takes any value. From equations (9) and (18), when function (14) takes the extreme value, that is, $\partial L / \partial x_{i}=0$, the following can be obtained:

$$
P\left(x_{i}\right)^{P-1} U_{i}^{T} K_{0} U_{i}=\lambda_{0} V_{i} .
$$

Taking equation (9) into equation (19) and multiplying $x_{i}^{m}$ at both ends of the equation, the following is obtained:

$$
P\left(x_{i}\right)^{m-1} U_{i}^{T} K U_{i}=\lambda_{0} V_{i} x_{i}^{m} .
$$

Let $\varepsilon_{i}=\left(x_{i}\right)^{m-1} U_{i}^{T} K U_{i}$, and substitute it into equation

$$
\begin{aligned}
& x_{i}=\left(\frac{P \varepsilon_{i}}{\lambda_{0} V_{i}}\right)^{\frac{1}{m}}\left(x_{\min }<x_{i} \leq 1\right), \\
& x_{i}=\left(\frac{\varepsilon_{i}}{V_{i}}\right)^{1 / m}\left\{\frac{f V_{0}+\sum_{j=1}^{k} V_{j} x_{\min }}{\sum_{j=1}^{n} V_{j}\left(\varepsilon_{j} / V_{j}\right)^{1 / m}}\right\}\left(x_{\min }<x_{i} \leq 1\right) .
\end{aligned}
$$

Here, $k$ represents the number of elements $x_{i} \leq 1$ and the iterative equation of $x_{\mathrm{i}}$ can be expressed as follows:

When $\quad x_{\min }<x_{i} \leq 1, \quad x_{i}=\left(\varepsilon_{i} / V_{i}\right)^{1 / m}\left\{\left(f V_{0}+\sum_{j=1}^{k}\right.\right.$ $\left.\left.V_{j} x_{\min }\right) /\left(\sum_{j=1}^{n} V_{j}\left(\varepsilon_{j} / V_{j}\right)^{1 / m}\right)\right\}$

When $x_{i}>1$, it is not in line with the actual situation, so $x_{i}^{z+1}=1$

When $x_{i} \leq x_{\min }$, the relative density exceeds the lower limit, so $x_{i}^{z+1}=x_{\text {min }}$

The above list is the mathematical calculation process of applying the Lagrange multiplier method to solve topology optimization problems based on the variable density method. As long as the volume ratio before and after topology optimization is limited, the virtual density of each unit in the design space can be calculated through a certain number of iterations. If the density of a place is 1 , it means that it is reserved; if the density is zero, it means that it is set as a hole; if the density is between the two, it means that part of it is reserved, so the topology optimization problem can be solved.

The topology optimization process in ANSYS Workbench is shown in Figure 8.

\subsection{Topology Optimization Analysis}

4.2.1. Topological Matrix Model. Before topology optimization of structures, it is necessary to establish a reasonable matrix model for topology optimization. In general, the initial model should be larger than or equal to the outer dimension of the original structure. According to the design input of receiving boom, discharging boom, and main tower overall shape and actual working condition, the topology optimization matrix model of key parts as shown in Figure 9 is established by using SolidWorks software.

4.2.2. Topology Optimization Calculation. Topology optimization is completed on the premise that the strength and stiffness meet the requirements. In ANSYS Workbench, the design variables, objective functions, and constraints are defined, and the value of residual material proportion $k$ is set, which is consistent with the value of residual material proportion $k$ set by the Lagrange multiplier method in the previous theory. The topology optimization module can iterate the relative density according to the input percentage of retained materials and finally remove the region of materials with a relative density of less than 1 . After the previous calculation, the percentage of retained material is in the range of $70 \% \sim 90 \%$, and the convergence effect is good. Five groups of topology optimization calculations with material removal percentages of $15 \%, 16 \%, 17 \%, 18 \%, 19 \%$, and $20 \%$ are carried out for receiving boom and discharging boom structure. The topology structure diagram is shown in Figures 10 and 11.

Five groups of topology optimization calculation with material removal percentages of $17 \%, 18 \%, 19 \%, 20 \%, 21 \%$, and $22 \%$ are carried out for the main tower structure. The topology structure is shown in Figure 12.

According to the uniformity and rationality of the structure distribution obtained by topology optimization of different $k$ values, and combined with the particularity of field application conditions, $k=0.18$ is adopted for the receiving arm, discharging arm, and the main tower as the basis for subsequent reconstruction.

4.2.3. Model Reconstruction after Optimization. There are many irregular parts in the model after topology optimization, so we need to follow the principle of manufacturability when reconstructing the model:

(1) In the process of repairing the model, we need to consider manufacturability. We need to use the straight bar instead of the bending part in the topology optimization results. On the one hand, the bending web member is not easy to produce, which will increase the production cost; on the other hand, the bent web member may affect the installation of other parts. Therefore, under the condition of keeping the whole structure unchanged, the bending web members after topology optimization are changed into straight web members

(2) Because not all cell densities are 0 or 1 after topology optimization, there are some unreasonable local positions that need to be modified in the topology optimization results. When repairing the model, it should be noted that the color lighter part is the middle density unit, which is the removable unit

(3) To ensure the lightweight of the boom, we try to use the bar to replace the plate, which can also maximize the lightweight of the boom

(4) In the reconstruction process, we try to make the members form a triangle connection, because more triangles will make the boom structure more stable and the stiffness of the boom will be improved

(5) The original structure of the connection part between the two ends of the boom and the rest of the rock spreader should not be changed as far as possible, so as to ensure the normal assembly of the parts 


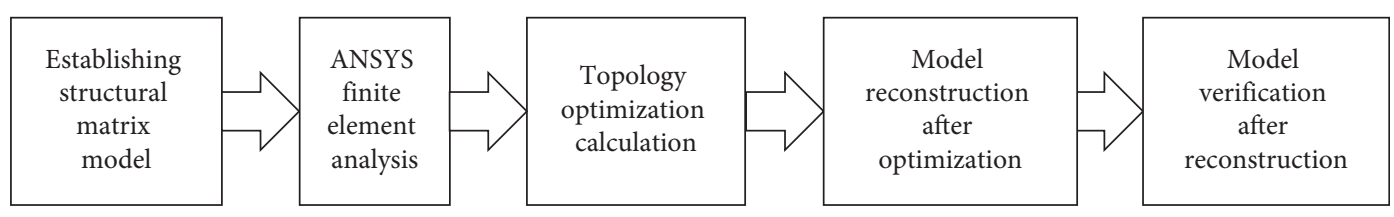

Figure 8: Topology optimization process.
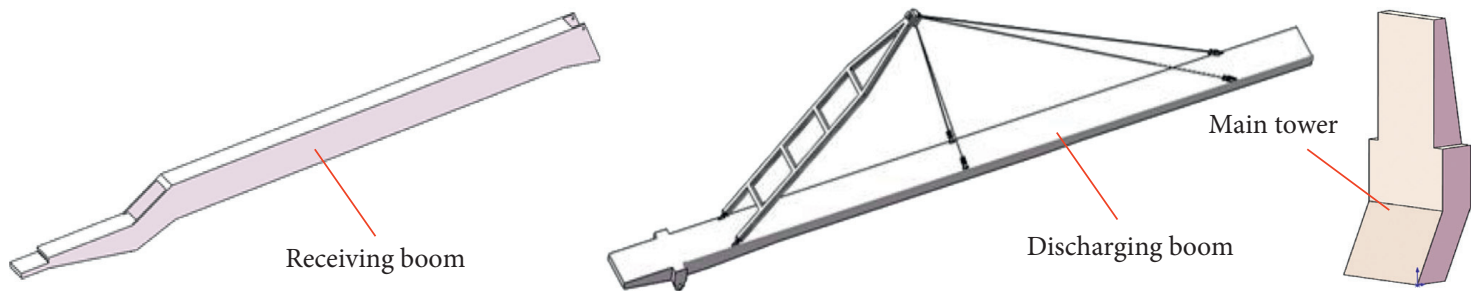

Figure 9: Topological matrix model.

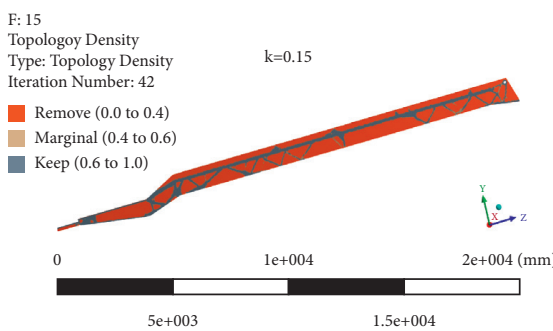

G: 16

Topologoy Density

Type: Topology Density

Iteration Number: 46

Remove $(0.0$ to 0.4$)$

Marginal (0.4 to 0.6)

Keep (0.6 to 1.0)

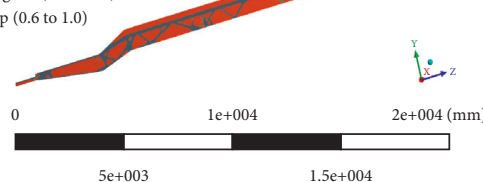

$5 e+003$

I: 19

C: 18
Topologoy Density

Topologoy Density
Type: Topology Density

Type: Topology Density
Iteration Number: 37

Remove (0.0 to 0.4$)$

Marginal (0.4 to 0.6$)$

Keep (0.6 to 1.0)

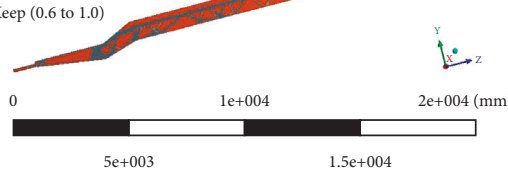

Topologoy Density

Iteration Number: 40

Remove (0.0 to 0.4$)$

Marginal (0.4 to 0.6$)$

Keep (0.6 to 1.0)
Type: Topology Density

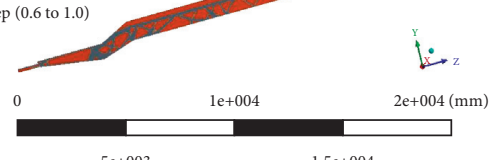

$5 e+003$

$1.5 e+004$ $\mathrm{k}=0.16$
H: 17

Topologoy Density

Type: Topology Density $\quad \mathrm{k}=0.17$

Iteration Number: 42

Remove (0.0 to 0.4)

Marginal (0.4 to 0.6$)$

Keep (0.6 to 1.0)

FIgURE 10: Topological structure of receiving boom.

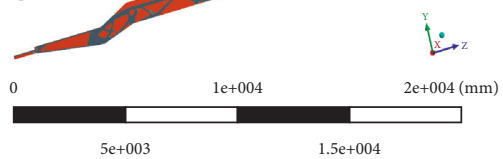

B: 20

Type: Topology Density

Type: Topology Den

Remove $(0.0$ to 0.4$)$

Marginal $(0.4$ to 0.6$)$

Keep (0.6 to 1.0)

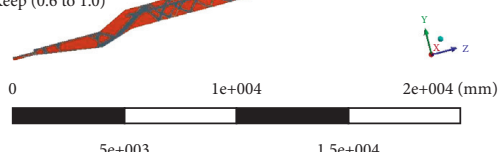

$5 \mathrm{e}+003$

$1.5 \mathrm{e}+004$
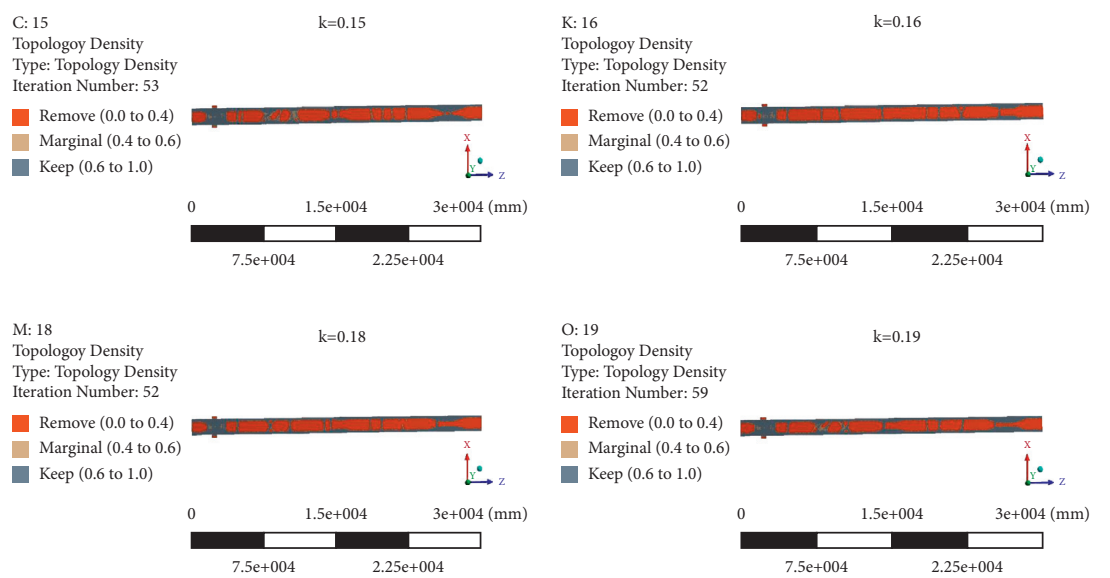

L: 17

Topologoy Density

Type: Topology Density

Iteration Number: 57

Remove (0.0 to 0.4)

Marginal (0.4 to 0.6)

- Keep (0.6 to 1.0$)$
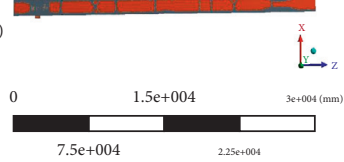

$\mathrm{R}: 20$

Topologoy Density

Iteration Number: 53

Remove (0.0 to 0.4$)$

Marginal $(0.4$ to 0.6$)$

Keep (0.6 to 1.0)
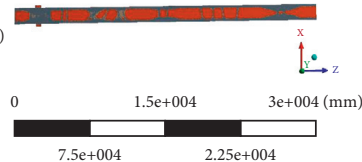

Figure 11: Topological structure of discharging boom. 


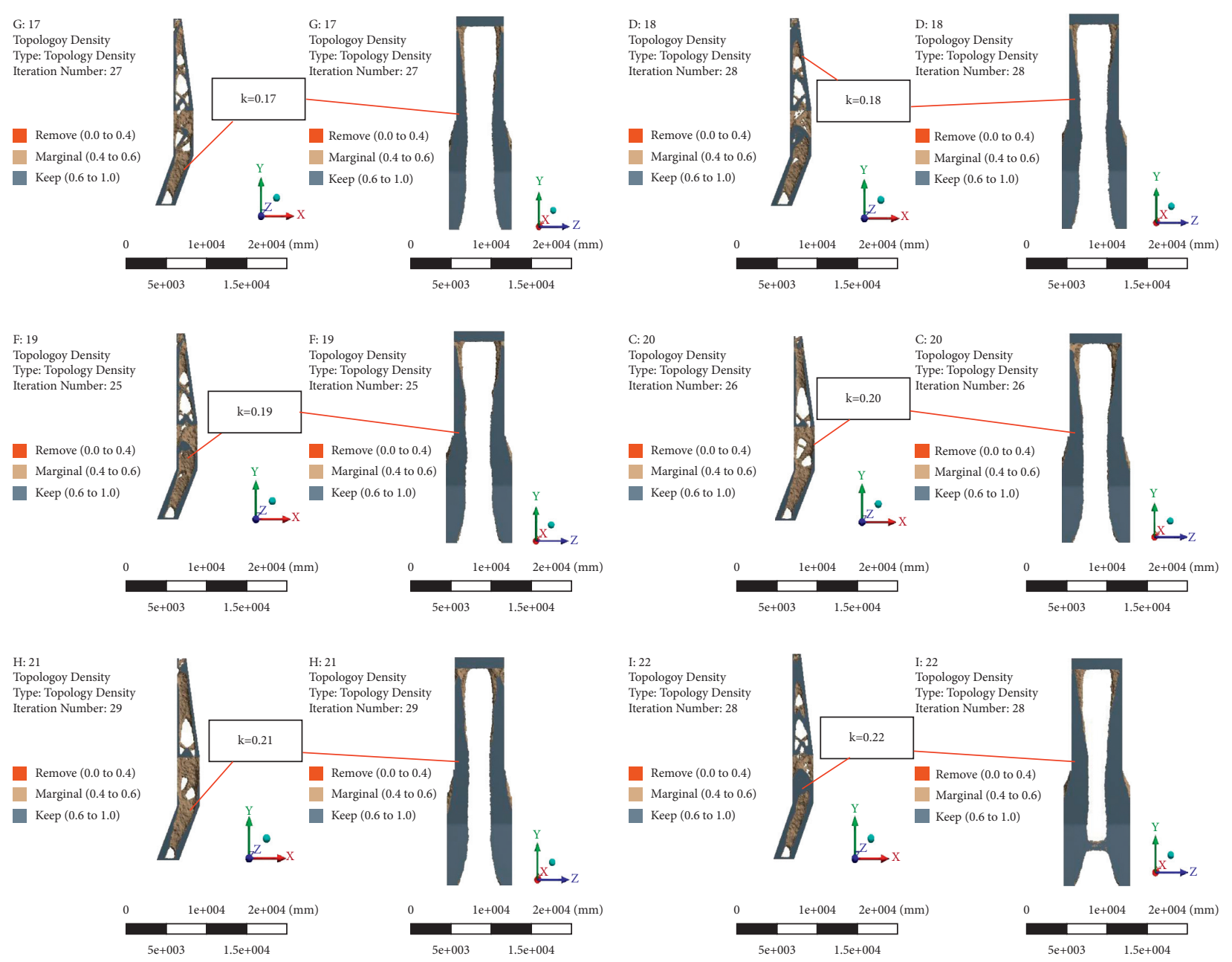

Figure 12: Topological structure of the main tower.

The optimized models of receiving boom, discharging boom, and main tower are shown in Figure 13. The weight comparison of key parts before and after optimization is shown in Table 7.

\subsubsection{Model Verification after Optimization}

(1) Verification of Receiving Boom after Optimization. Referring to the previous method and the process of calculating the static and dynamic characteristics of the receiving boom, the static simulation and modal analysis of the optimized receiving boom are carried out. The deformation and stress distribution of the receiving boom under optimized condition III are shown in Figure 14; the comparison of deformation and stress before and after optimization is shown in Table 8. The low-order modal shapes of the optimized boom are shown in Figure 15, and the dynamic performance comparison before and after optimization is shown in Table 9.

It can be seen from Figure 14 and Table 8 that, under the worst condition III, the maximum deformation of the receiving boom after optimization is reduced by $10.8 \%$ compared with that before optimization. The maximum stress is increased by $6.2 \%$, but it is still in the safe range, and the stress of the optimized boom tends to be uniform, so it is obvious that the new structure is more reasonable.

According to Figure 15 and Table 9, after optimization, the multistage amplitude of the receiving boom decreases, and its stiffness is improved to a certain extent. After optimization, all low-order natural frequencies of the boom are improved to a certain extent, especially the 5th-order frequency is changed from $6.78 \mathrm{~Hz}$ to $9.32 \mathrm{~Hz}$, which is $38.68 \%$ higher than that before optimization, avoiding the resonance band caused by the idler. The improvement of the natural frequency of the receiving boom means the improvement of the overall stiffness of the boom, which makes the operation of the rock spreader more stable.

(2) Verification of Discharging Boom after Optimization. Referring to the previous method and the process of calculating the static and dynamic characteristics of the discharging boom, the static simulation and modal analysis of the optimized discharging boom are carried out. The deformation and stress distribution of the discharging boom under optimized condition III are shown in Figure 16. The comparison of deformation and stress before and after 


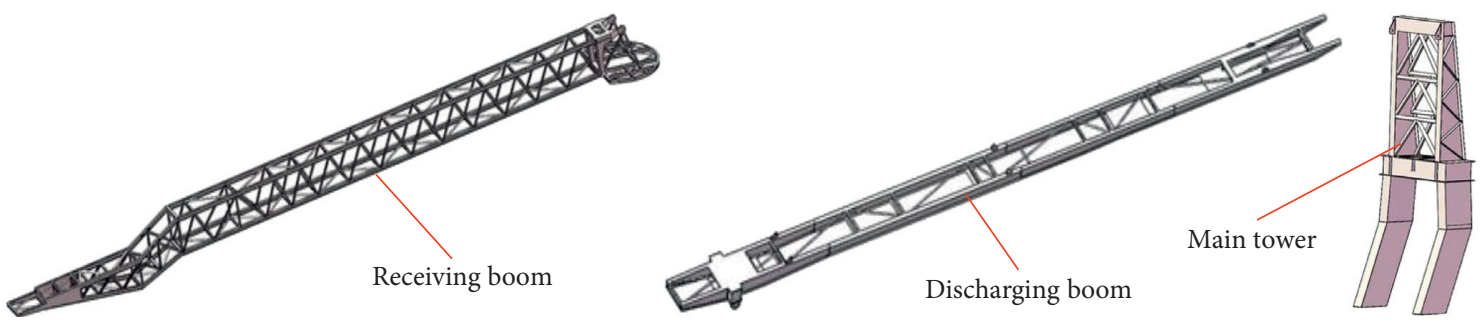

Figure 13: Model reconstruction after topology optimization.

TABLE 7: Weights comparison of key parts before and after optimization.

\begin{tabular}{lccc}
\hline Parameter name & Before optimization & After optimization & Changes $(\%)$ \\
\hline Receiving boom $(\mathrm{kg})$ & 35917 & 34125 & -5 \\
Discharging boom $(\mathrm{kg})$ & 26303 & 25222 & -4.1 \\
Main tower $(\mathrm{kg})$ & 41429 & 39652 & -4.5 \\
\hline
\end{tabular}
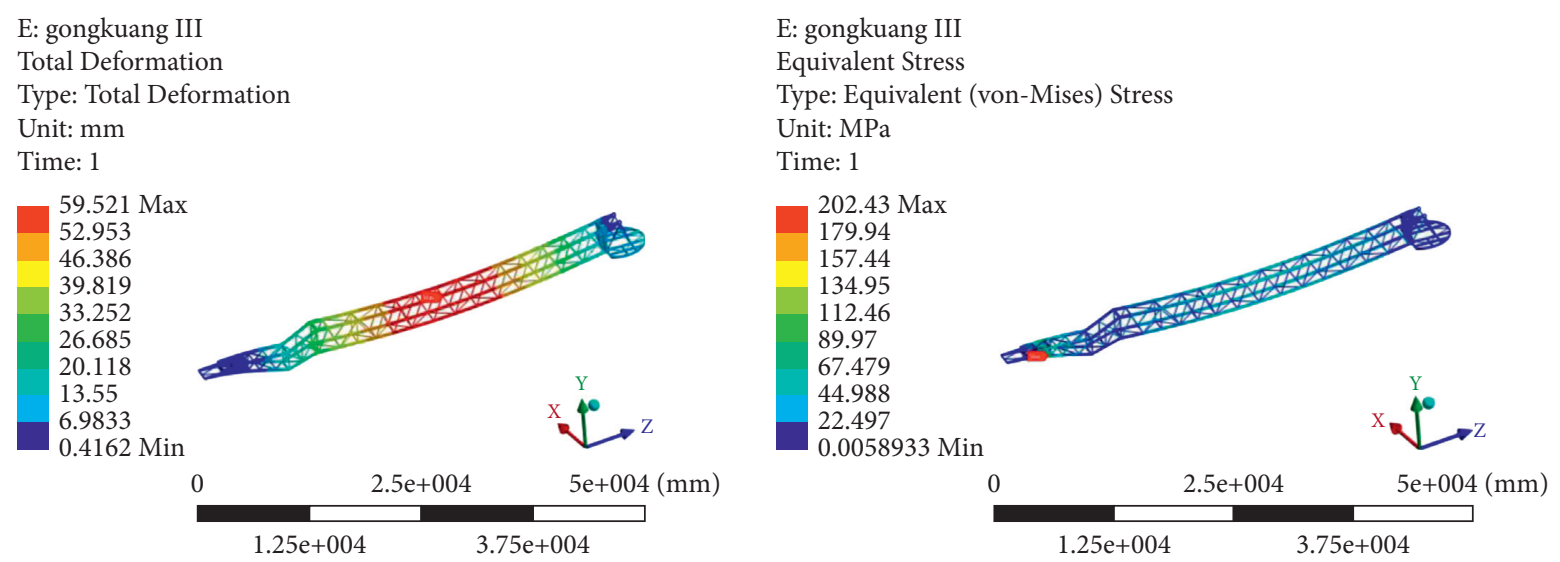

FIGURE 14: Deformation and stress nephogram of the optimized receiving boom under condition III.

TABLE 8: Comparison of maximum stress and deflection before and after optimization of receiving boom.

\begin{tabular}{lccc}
\hline Parameter name & Before optimization & After optimization & Changes $(\%)$ \\
\hline Maximum deflection deformation $(\mathrm{mm})$ & 66.74 & 59.52 & -10.8 \\
Maximum stress $(\mathrm{MPa})$ & 190.67 & 202.43 & +6.2 \\
\hline
\end{tabular}

optimization is shown in Table 9. The low-order modal shapes of the optimized discharging boom are shown in Figure 17, and the dynamic performance comparison before and after optimization is shown in Table 10.

It can be seen from Figure 16 and Table 10 that under the worst condition III, the maximum deformation of the optimized discharging boom increases by $12.7 \%$, and the maximum stress increases by $16.8 \%$, but they are within the safe range. It is worth noting that the maximum stress and deformation of the new structure are more evenly distributed and the design is more reasonable.

It can be seen from Figure 17 and Table 11 that the fifthorder frequency of the discharging boom before the optimization is within the resonant frequency range of the idler, while the first five order modes after optimization avoid the resonant frequency of the idler, which improves the dynamic characteristics of the discharging boom to a certain extent.
(3) Verification of the Whole Machine Virtual Prototype. To verify whether the structure of the rock spreader meets the overall load requirements after optimization, the optimized receiving boom, discharging boom, and main tower are reconstructed and verified by finite element analysis.

The action of the receiving boom is the most frequent during the operation of the rock spreader. This section mainly focuses on the stress and deformation of the receiving boom of the rock spreader under the rated load, wind load, and seismic load at the upper, horizontal, and lower positions. Finite element analysis is carried out for the whole machine model assembled after topology optimization, in which the material properties, loads, and boundary conditions are set the same as those for single part analysis, and the finite element model is shown in Figure 18.

The simulation analysis is carried out for the three main positions of the upper row, the lower row, and the horizontal row of the rock spreader under dangerous working 
B: Modal

Total Deformation

Type: Total Deformation

Frequency: $4.1115 \mathrm{~Hz}$

Unit: $\mathrm{mm}$

0.33384 Max
0.29675
0.25965
0.22256
0.18547
0.14837
0.11128
0.074187
0.037093
0 Min

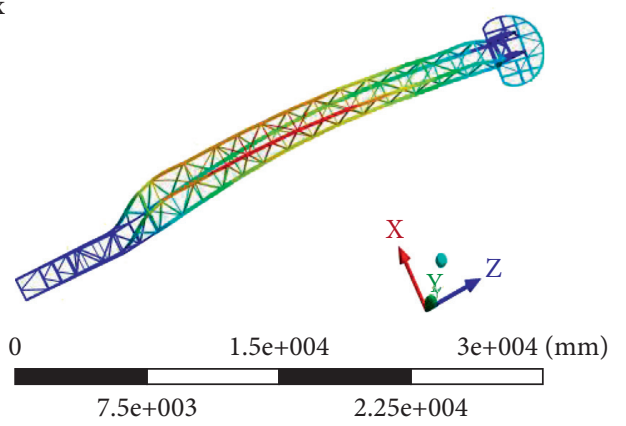

(a)

B: Modal

Total Deformation 3

Type: Total Deformation

Frequency: $6.6499 \mathrm{~Hz}$

Unit: $\mathrm{mm}$
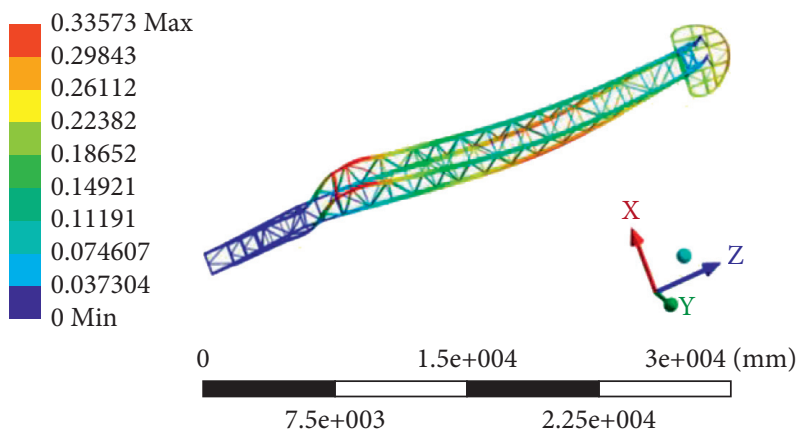

(c)

B: Modal

Total Deformation 5

Type: Total Deformation

Frequency: $10.541 \mathrm{~Hz}$

Unit: $\mathrm{mm}$
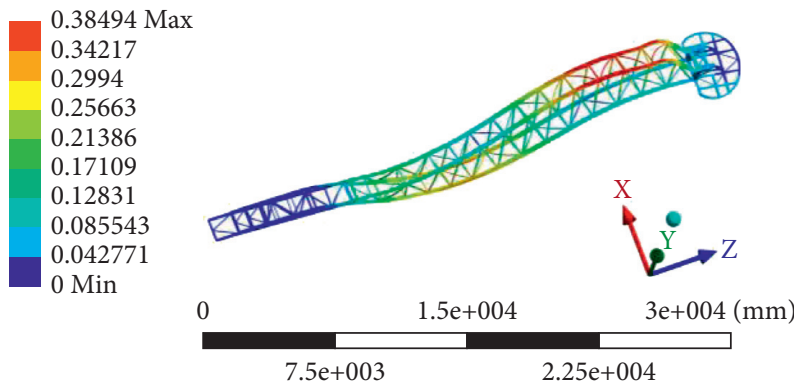

(e)
B: Modal

Total Deformation 2

Type: Total Deformation

Frequency: $4.1584 \mathrm{~Hz}$

Unit: $\mathrm{mm}$

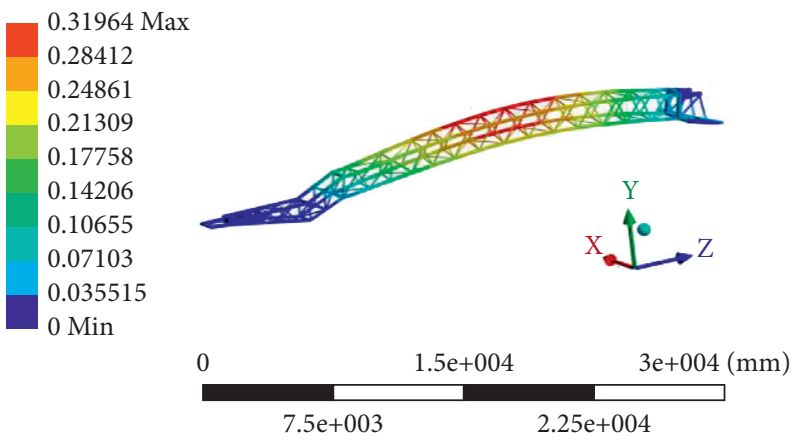

(b)

B: Modal

Total Deformation 4

Type: Total Deformation

Frequency: $9.3212 \mathrm{~Hz}$

Unit: $\mathrm{mm}$
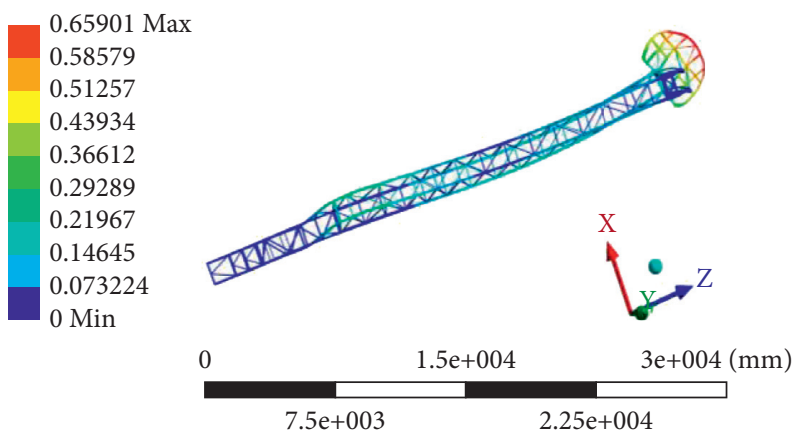

(d)

B: Modal

Total Deformation 6

Type: Total Deformation

Frequency: $11.261 \mathrm{~Hz}$

Unit: $\mathrm{mm}$

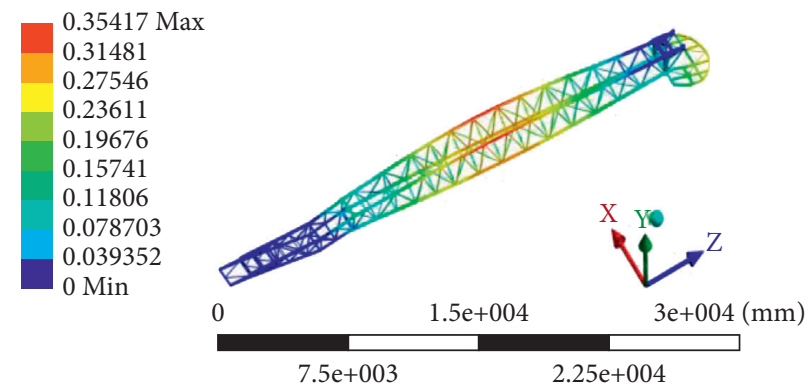

(f)

Figure 15: The vibration mode diagram of the first six modes of the receiving boom after optimization. (a) The first mode. (b) The second mode. (c) The third mode. (d) The fourth mode. (e) The fifth mode. (f) The sixth mode.

conditions. The deformation and stress nephogram of three different working positions are shown in Figure 19-21.

It can be seen from Figures 19-21 and Table 12 that the maximum deformation under three different working conditions occurs at the midspan position of the receiving boom. The maximum stress occurs at the vertical steel plate on the left side of the receiving boom. Among them, the maximum deflection and maximum stress of the rock spreader under the upper discharge condition are larger, which are $57.72 \mathrm{~mm}$ and $218.41 \mathrm{MPa}$, respectively, but both 
TABLE 9: Comparison of the dynamic performance of receiving boom before and after optimization.

\begin{tabular}{lccc}
\hline Frequency order & Before optimization & After optimization & Changes $(\%)$ \\
\hline 1 & 3.73 & 4.11 & +10.19 \\
2 & 4.12 & 4.16 & +0.97 \\
3 & 5.02 & 6.65 & +32.47 \\
4 & 6.78 & 9.32 & +37.46 \\
5 & 7.60 & 10.54 & +38.68 \\
6 & 10.46 & 11.26 & +7.65 \\
\hline
\end{tabular}

U: gongkuang III

Total Deformation

Type: Total Deformation

Unit: $\mathrm{mm}$

Time: 1

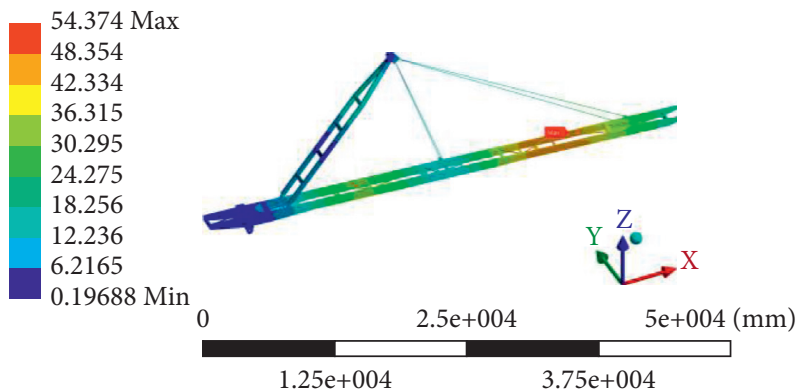

U: gongkuang III

Equivalent Stress

Type: Equivalent (von-Mises) Stress

Unit: $\mathrm{MPa}$

Time: 1

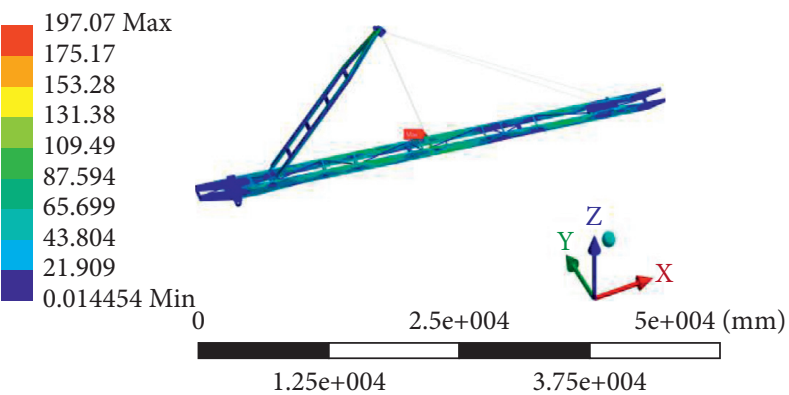

FIGURE 16: Deformation and stress nephogram of the optimized discharging boom under condition III.

Total Deformation

Type: Total Deformation

Frequency: $1.4377 \mathrm{~Hz}$

Unit: $\mathrm{mm}$
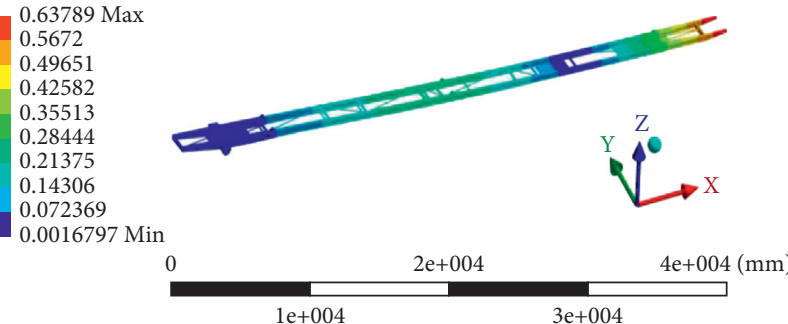

(a)

Total Deformation 3

Type: Total Deformation

Frequency: $4.681 \mathrm{~Hz}$

Unit: $\mathrm{mm}$

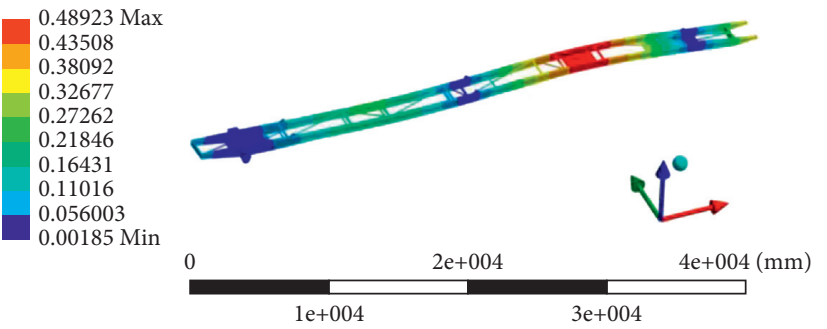

(c)
Total Deformation 2

Type: Total Deformation

Frequency: $3.2319 \mathrm{~Hz}$

Unit: $\mathrm{mm}$
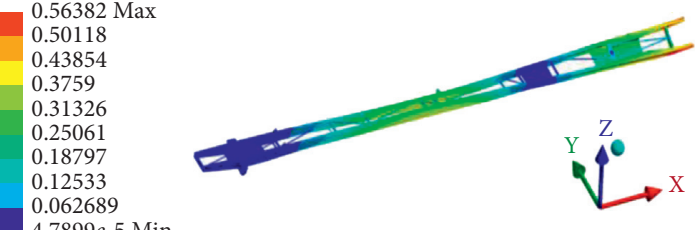

$4.7899 e-5 \mathrm{Min}$

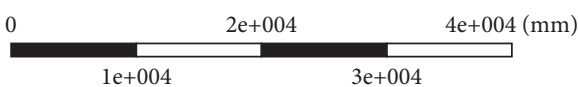

(b)

Total Deformation 4

Type: Total Deformation

Frequency: $5.0944 \mathrm{~Hz}$

Unit: $\mathrm{mm}$

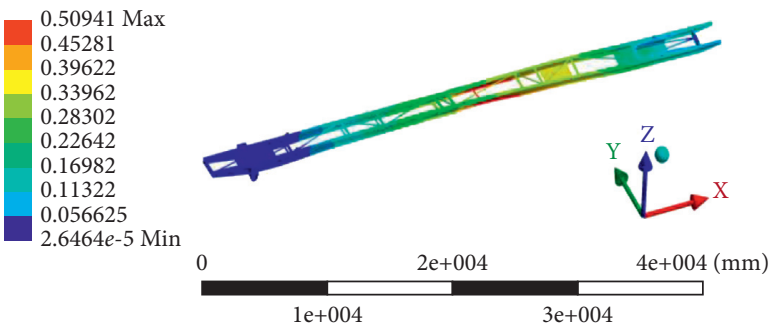

(d)

Figure 17: Continued. 


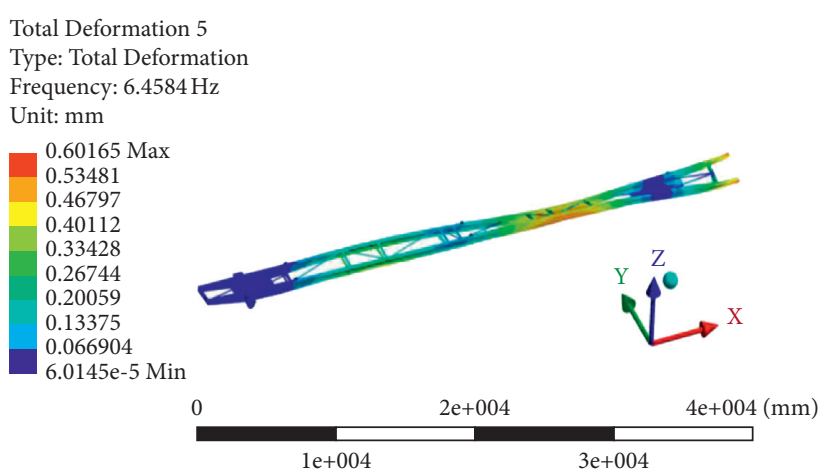

(e)

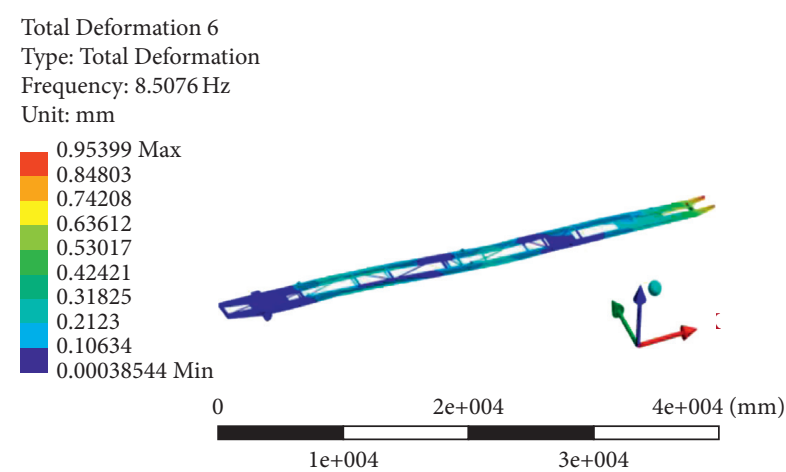

(f)

Figure 17: The vibration mode diagram of the first six modes of the discharging boom after optimization. (a) The first mode. (b) The second mode. (c) The third mode. (d) The fourth mode. (e) The fifth mode. (f) The sixth mode.

TABle 10: Comparison of maximum stress and deflection before and after optimization of discharging boom.

\begin{tabular}{lccc}
\hline Parameter name & Before optimization & After optimization & Changes $(\%)$ \\
\hline Maximum deflection deformation $(\mathrm{mm})$ & 48.26 & 54.37 & +12.7 \\
Maximum stress $(\mathrm{MPa})$ & 168.77 & 197.07 & +16.8 \\
\hline
\end{tabular}

TABle 11: Comparison of dynamic performance of discharging boom before and after optimization.

\begin{tabular}{lccc}
\hline Frequency order & Before optimization & After optimization & Changes (\%) \\
\hline 1 & 1.68 & 1.44 & -14.28 \\
2 & 3.37 & 3.23 & -4.15 \\
3 & 4.78 & 4.68 & -2.09 \\
4 & 6.59 & 5.09 & -22.76 \\
5 & 8.36 & 6.46 & -22.73 \\
6 & 8.93 & 8.51 & -4.70 \\
\hline
\end{tabular}

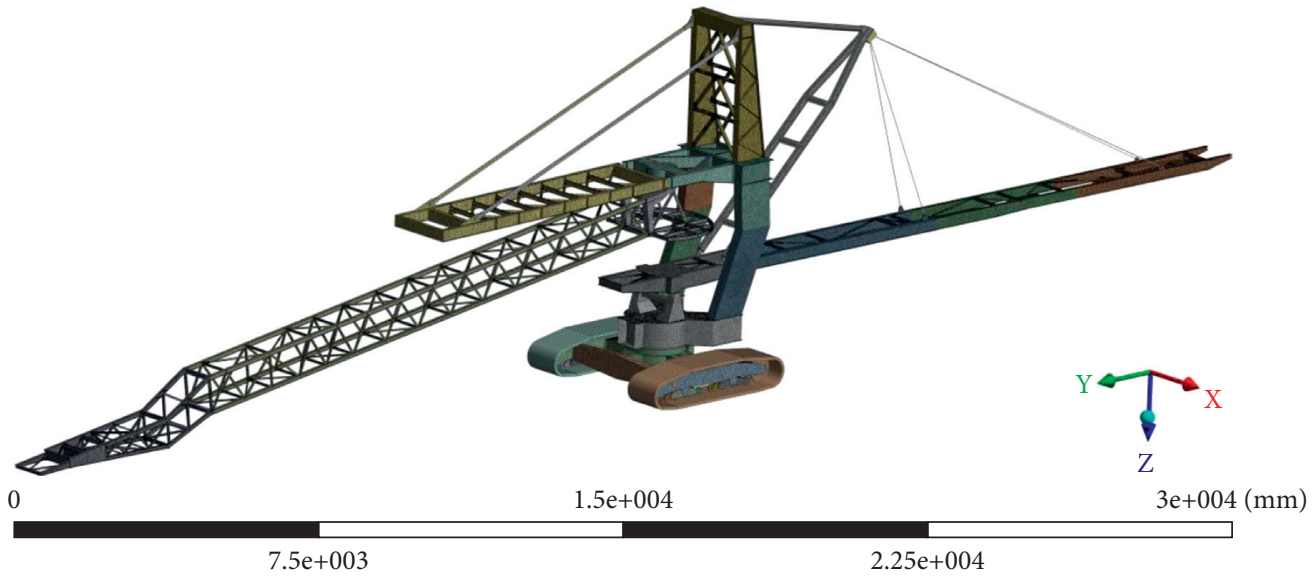

FIgURE 18: Assembly machine model after topology optimization.

are within the safe range and meet the engineering requirements. It can be seen from Table 7 that the weight of the receiving boom, discharging boom, and main tower is reduced by $5 \%, 4.1 \%$, and $4.5 \%$, respectively. It can be seen that the topology lightweight of each key structural part not only reduces the weight of the whole machine and reduces the production cost and power of the equipment but also reduces the grounding pressure of the rock spreader to a certain extent and improves the safety of the rock spreader. 
A: shangpai

Total Deformation

Type: Total Deformation

Unit: $\mathrm{mm}$

Time: 1

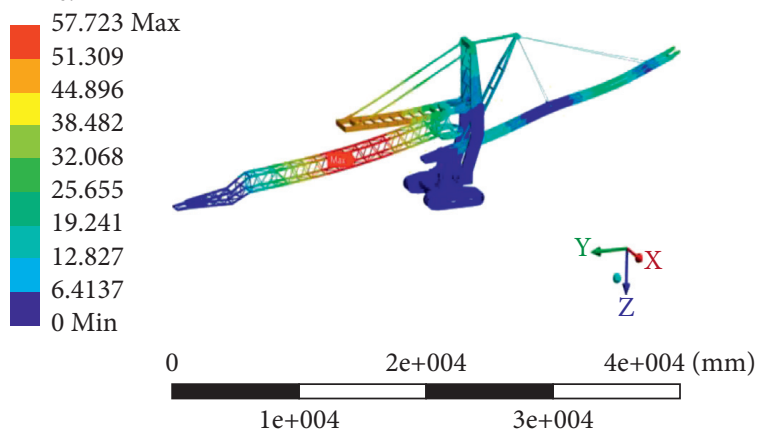

A: shangpai

Equivalent Stress

Type: Equivalent (von-Mises) Stress

Unit: MPa

Time: 1

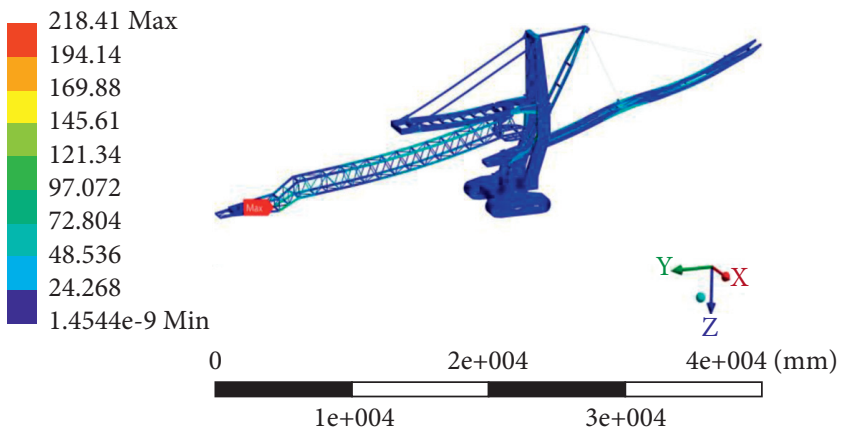

FIgURE 19: Deflection deformation and stress nephogram of the whole machine structure under the upper position.

A: Static Structural

Total Deformation

Type: Total Deformation

Unit: $\mathrm{mm}$

Time: 1

56.258 Max
50.007
43.756
37.505
31.255
25.004
18.753
12.502
6.2509
0 Min

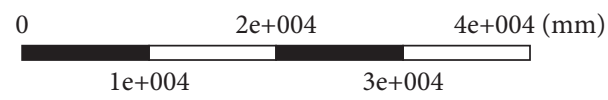

A: Static Structural

Equivalent Stress

Type: Equivalent (von-Mises) Stress

Unit: $\mathrm{MPa}$

Time: 1

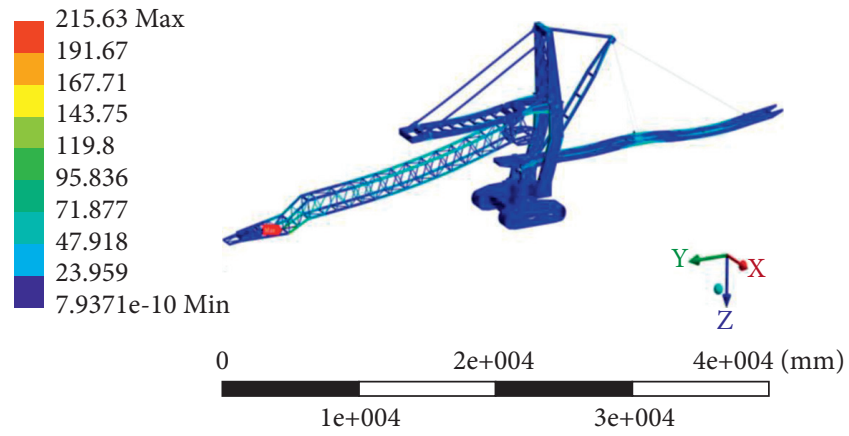

FIGURE 20: Deflection deformation and stress nephogram of the whole machine structure under the horizontal position.

\begin{abstract}
A: Static Structura
Unit: $\mathrm{mm}$

Time: 1

$56.3 \mathrm{Max}$
50.045
43.789
37.533
31.278
25.022
18.767
12.511
6.2556
0 Min
\end{abstract}

Total Deformation

Type: Total Deformation
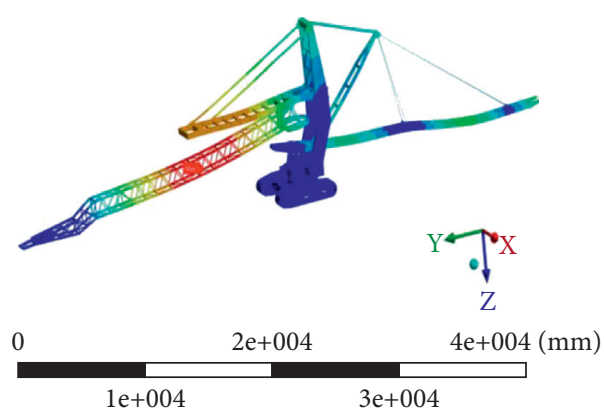

A: Static Structural

Equivalent Stress

Type: Equivalent (von-Mises) Stress

Unit: MPa

Time: 1
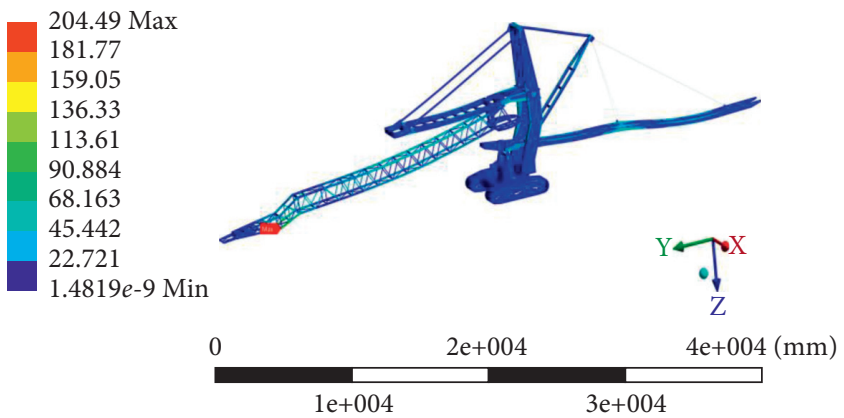

Figure 21: Deflection deformation and stress nephogram of the whole machine structure under the lower position. 
TABLE 12: Maximum deformation and stress values of rock spreader at different working positions.

\begin{tabular}{lcc}
\hline Parameter name & Maximum deflection deformation $(\mathrm{mm})$ & Maximum stress $(\mathrm{MPa})$ \\
\hline The upper position & 57.72 & 218.41 \\
The horizontal position & 56.26 & 215.63 \\
The lower position & 56.30 & 204.49 \\
\hline
\end{tabular}

\section{Conclusion}

(1) The actual load characteristic analysis, structural topology optimization and reconstruction, static and dynamic simulation of each optimized part, and static and dynamic performance analysis of the whole machine verify the correctness of the optimization of the key structure of the rock spreader. A set of topology optimization design theories and methods suitable for the key main structural parts of a large rock spreader is formed, which solves the problems of its large vibration and poor discharge uniformity

(2) After the topology optimization of the key parts, the following conclusions are obtained in terms of stability. (1) The multistage amplitude of the receiving boom decreases, which improves its stiffness to a certain extent. And its low-order natural frequencies are improved, avoiding the resonance band caused by the idler. (2) The first five modes of the discharging boom avoid the resonance frequency of the idler, which improves the dynamic characteristics of the boom to a certain extent. (3) Compared with before optimization, the weight of receiving boom, discharging boom, and main tower can be reduced by $5.0 \%, 4.1 \%$, and $4.5 \%$, respectively, but their stress distributions are more uniform and their structures are more reasonable

(3) The optimized key structures of the rock spreader are assembled and the virtual prototype is established. Under the worst working conditions, the maximum deflection deformation and the maximum equivalent stress of the receiving boom, discharging boom, and main tower after optimization are in the safe range, which can meet the working requirements of the rock spreader. The correctness of topology optimization lightweight design is verified.

\section{Data Availability}

The data used to support the findings of this study are available from the corresponding author upon request.

\section{Conflicts of Interest}

The authors declare that they have no conflicts of interest.

\section{Acknowledgments}

This work was supported by the Foundations of Key R\&D Projects of Shanxi Province (International Scientific and Technological Cooperation), China (Grant no.
201803D421041), Major Science and Technology Projects of Shanxi Province, China (Grant no. 20181101017), and Applied Basic Research Project of Shanxi Province, China (Grant no. 201701D121017).

\section{References}

[1] C. G. Gong, Z. F. Bian, H. F. Bian et al., "Key technology of DEM model construction based on UAV and vegetation index in dump soil field," Journal of China Coal Society, vol. 44, no. 12, pp. 3849-3858, 2019.

[2] Y. Zhou, "Dynamic analysis of statically determinate portal structure of double-crawler spreader," Master's Thesis, Tsinghua University, Beijing, China, 2012.

[3] L. F. Ma, Z. Yang, Y. Zhang, Z. X. Wang, F. B. Wu, and Z. Q. Yao, "Technical development and application of heavy spreader," Heavy Machinery, vol. 2020, no. 5, pp. 14-18, 2020.

[4] Z. Z. Zhang, "Study on mining technology in the second mining area of weijiamao open-pit coal mine," master's thesis, Inner Mongolia University of Science \& Technology, Inner Mongolia, Baotou, China, 2014.

[5] H. Zhong, "Application of semi continuous mining technology in open pit mine," Coal Engineering, vol. 42, no. 10, pp. 7-9, 2012.

[6] T. M. Han, "Selection and design of related equipment for production system in Apartak Open -pit Coal Mine," Open pit mining technology, vol. 36, no. 3, pp. 84-86, 2021.

[7] J. Chang, T. Hu, X. Liu, and X. Ren, "Construction of green infrastructure in coal-resource based city: a case study in Xuzhou urban area," International Journal of Coal Science \& Technology Technology, vol. 5, no. 1, pp. 92-104, 2018.

[8] N. D. Rose and O. Hungr, "Forecasting potential rock slope failure in open pit mines using the inverse-velocity methodCase examples," in Proceedings of the 1st Canada-US Rock Mechanics Symposium-Rock Mechanics Meeting Society's Challenges and Demands, Vancouver, Canada, May 2007.

[9] W. Zhu, Y. Zhang, Z. K. Liu, and Q. Zhu, "Pre- and postcollapse ground deformation revealed by sar interferometry: a case study of foshan (China) ground collapse," Journal of Sensors, vol. 2020, Article ID 8899054, 17 pages, 2020.

[10] X. T. Ai, G. J. Wang, C. Zhang et al., "Stability analysis of high dump with wide graded waste rock," Rock and Soil Mechanics, vol. 41, no. 11, pp. 3777-3788, 2020.

[11] G. Baer, Y. Magen, R. N. Nof, E. Raz, V. Lyakhovsky, and E. Shalev, "InSAR measurements and viscoelastic modeling of sinkhole precursory subsidence: implications for sinkhole formation, early warning, and sediment properties," Journal of Geophysical Research: Earth Surface, vol. 123, no. 4, pp. 678-693, 2018.

[12] G. Chen, Y. Zhang, R. Zeng et al., "Detection of land subsidence associated with land creation and rapid urbanization in the Chinese loess plateau using time series InSAR: a case study of Lanzhou New District," Remote Sensing, vol. 10, no. 2, p. 270, 2018. 
[13] X. W. Yang, Y. M. Chen, Y. L. Zhao, L. L. Gao, and Y. F. Jing, "Experimental study on seepage in No.2 dump of dapo iron mine," Coal Technology, vol. 40, no. 6, pp. 150-155, 2021.

[14] F. Q. Wen, H. Y. Dong, J. Y. Feng, W. W. Yang, X. P. Qu, and L. P. Wang, "Optimizing management of high bench dumping process for dumping site in an open-cast mine," Metal Mine, vol. 501, no. 3, pp. 50-56, 2018.

[15] Z. L. Yang, J. M. Yang, Q. Li, and S. L. Jiang, "Determination of the largest bench height of belt dumping conveyor and the safety distance," Metal Mine, vol. 465, no. 3, pp. 63-67, 2015.

[16] S. F. Lu, Z. G. Liu, X. G. Zhang, and Y. M. Guan, "Design and optimization of the scalable feeding arm for dumping machine," Mining Research and Development, vol. 34, no. 1, pp. 85-88, 2014.

[17] M. Dong and Q. Luo, "Research and application on energy saving of port belt conveyor," Procedia Environmental Sciences, vol. 10, no. 10, pp. 32-38, 2011.

[18] W. K. Yang and W. L. Pu, "Optimization of limit device of PL2400 dumping machine supporting vehicle," Opencast Mining Technology, vol. 32, no. 10, pp. 53-55, 2017.

[19] H. Y. Dong and Y. M. Wang, "Stacking and discharging process design of rock extractor in a mine in Bayan Obo," Modern Mining, vol. 564, no. 4, pp. 263-265, 2016.

[20] X. Han, "Design and research on the cab of the dumping machine based on ergonomics," Master's Thesis, Taiyuan University of Technology, Taiyuan, China, 2020.

[21] H. N. Meng, J. J. Ren, A. F. Li, J. L. Li, and Y. K. Wang, "Research on layout optimization design of operation interface layoutin spreader," Machine Design and Research, vol. 36, no. 6, pp. $159-165,2020$.

[22] Q. L. Hu, J. H. Li, and S. J. Guo, "Design and reconstruction of dry oil concentrated lubrication system for tanker transportation system," Chemical Engineering Design Communications, vol. 43, no. 5, p. 246, 2017.

[23] Y. S. Zhang, "Discussion on the lubrication for the external tooth of slewing bearing in dumping plough," Science-technology Innovation and Productivity, vol. 298, no. 11, pp. 100-101, 2018.

[24] Z. Q. Yao, L. F. Ma, F. B. Wu, and W. Q. Pan, "Research and analysis on vibration of discharging arm conveyor of spreader," Coal Mine Machinery, vol. 41, no. 1, pp. 75-77, 2020.

[25] M. Ding, D. Geng, M. D. Zhou, and M. X. Lai, “Topology optimization strategy of structural strength based on variable density method," Journal of Shanghai Jiaotong University, vol. 55, no. 6, pp. 764-773, 2021.

[26] N. Pollini and O. Amir, "Mixed projection- and density-based topology optimization with applications to structural assemblies," Structural and Multidisciplinary Optimization, vol. 61, no. 2, pp. 687-710, 2020.

[27] R. Picelli, S. Townsend, C. Brampton, J. Norato, and H. A. Kim, "Stress-based shape and topology optimization with the level set method," Computer Methods in Applied Mechanics and Engineering, vol. 329, no. 2, pp. 1-23, 2018.

[28] F. Y. Huang, "The topology optimization design of liner replacement manipulator on mill," Master's Thesis, Jiangxi University of Science and Technology, Ganzhou, China, 2017.

[29] J. Fu, "Structural optimization and lightweight design of a dump truck frame," Master's Thesis, Jiangsu University, Zhenjiang, China, 2020.

[30] W. D. Wu, Z. X. Yang, J. Li, and J. T. Dai, "Load analysis and structure optimization of rock scraping operation of driving arm of hydraulic excavating machine," Coal Mine Machinery, vol. 42, no. 3, pp. 85-88, 2021.
[31] H. P. Tang, H. X. Li, Y. Z. Jiang, and J. Liu, "Structural design of key components of feeder based on topology optimization and multi-objective optimization," Journal of Mechanical Strength, vol. 42, no. 4, pp. 842-848, 2020.

[32] Y. M. Pang, Y. B. Wang, X. H. Li, W. H. Li, and J. J. Ren, "Finite element analysis and structure optimization on track frame of WK-75 mine excavator," Mining Research and Development, vol. 39, no. 1, pp. 100-105, 2019.

[33] X. X. Liu, "Feasibility Analysis and Technical Scheme Study on Land Loss Mining in Baoli Open-Pit Coal Mine," Master's Thesis, China University of Mining and Technology, Xuzhou, China, 2019.

[34] P. Xue, "The design and analysis of the discharge arm based on the quality control," Master's Thesis, Northeastern University, Shenyang, China, 2014.

[35] J. J. Xiao, "The dynamic simulation research on gantry crane based on virtual prototype technology," Master's Thesis, Southwest Jiaotong University, Chengdu, China, 2008.

[36] L. Wang, "Finite element analysis for bucket wheel stackerreclaimer and optimal design for the structure of forearm," Master's Thesis, Wuhan University of Technology, Wuhan, China, 2014.

[37] W. J. Zhang, Mobile Equipment for Continuous Handling of Bulk Materials Rules for the Design of Steel Structures, China Standards Press, Beijing, China, 2005.

[38] L. Wan, G. N. Xu, D. M. Gu et al., Design Rules of Cranes, China Standards Press, Beijing, China, 2008.

[39] S. Shi, L. J. Wang, H. Q. Yu et al., Code for Design of Steel Structures, China Standards Press, Beijing, China, 2017.

[40] L. Daryl and Logan, Fundamentals of Finite Element Method, Publishing House of Electronics Industry, Beijing, China, 3rd edition, 2003.

[41] A. Mmtm, H. L. Chen, and J. Wang, Introduction and Application of ANSYS Workbench 18.0 Finite Element Analysis, China Machine Press, Beijing, China, 2018.

[42] Z. J. Wang and L. M. Sun, ANSYS 18.0 Finite Element Analysis Foundation and Example Course, China Machine Press, Beijing, China, 2018.

[43] Y. W. Kang, Q. T. Guo, J. G. Ji, and C. W. Wang, "Finite element dynamic analysis of mill-foundation considering soilstructure interaction," Mining Machinery, vol. 41, no. 2, pp. 70-75, 2013.

[44] J. S. Liu, G. T. Parks, and P. J. Clarkson, "Topology/shape optimization of axisymmetric continuum structures metamorphic development approach," Structural and Muti-disciplinary Optimization, vol. 29, pp. 73-83, 2005.

[45] G. Z. Yu, "The finite element analysis and research on topology optimization technology for vehicle frame base on ANSYS workbench," Master's Thesis, Harbin Institute of Technology, Harbin, China, 2014.

[46] Y. S. Yin, "Topology optimization methods of continuum structure based on variable density method," Master's Thesis, Northeastern University, Shenyang, China, 2014. 